REVISTA DE DERECHO UNED, NÚM. 13, 2013

\title{
CUESTIONES RELEVANTES DE LA PRUEBA DE ALCOHOLEMIA EN EL PROCESO PENAL
}

\section{OUTSTANDING ISSUES OF ALCOHOL TEST IN CRIMINAL PROCEEDINGS}

\author{
ROSA SALVADOR CONCEPCIÓN \\ Abogada y Doctora en Derecho
}

María no recordaba nada, tan solo que le cegó el fuerte resplandor de dos faros circulando en sentido contrario al suyo.

Antonio tampoco recordaba nada, tan solo que todo el mundo le había insistido que en su estado no debia coger el coche.

Resumen: En el enjuiciamiento del Delito contra la Seguridad Vial por conducción bajo ingesta alcohólica surgen varias cuestiones que han resultado polémicas tanto en su tratamiento por la doctrina más consolidada como en la jurisprudencia, por lo que en las siguientes líneas vamos a tratar estas cuestiones tratando de dar una respuesta lo más ilustrada posible.

Palabras Clave: Seguridad vial, Alcohol, Test de Alcoholemia, Prueba, Negativa a someterse a las pruebas.

Abstract: In the prosecution of the Crime against the Road Security for conduction under alcoholic ingestion there arise several questions that have turned out to be polemic so much in his treatment for the doctrine most consolidated like in the jurisprudence, it 
is the reason that in the following lines we are going to treat these questions trying to give an as illustrated as possible response.

Key Words: Road Security, Alcohol, Test of Blood alcohol level, Test, Denial to surrender to the tests.

Recepción original: 10/07/2013

Aceptación original: 31/07/2013

Sumario: I. Introducción. II. El Delito contra la Seguridad Vial por Ingesta Alcohólica. III. Cuestiones Relevantes de su Enjuiciamiento. III.1. Posible Vulneración del Derecho a la Intimidad. III.2. Consecuencias de la Negativa a Realizar la Prueba. IV. Conclusiones.

\section{INTRODUCCIÓN}

Ante la posible comisión de un Delito contra la Seguridad Vial adquiere especial importancia el test de alcoholemia y son muchos los interrogantes que surgen entorno a la realización de esta prueba y a su relevancia en el enjuiciamiento de este delito.

De manera que en estas líneas voy a tratar todas estas cuestiones a la luz de la doctrina y la jurisprudencia más consolidada, así como finalmente realizaré acerca de las mismas una serie de conclusiones que espero resulten ilustrativas.

\section{EL DELITO CONTRA LA SEGURIDAD VIAL POR INGESTA ALCOHÓLICA}

El inciso segundo del artículo $379.2^{1}$ fija en 0,60 miligramos por litro en aire espirado o 1,2 gramos por litro en sangre la tasa de al-

\footnotetext{
1 «1. El que condujere un vehículo de motor o un ciclomotor a velocidad superior en sesenta kilómetros por hora en vía urbana o en ochenta kilómetros por hora en vía interurbana a la permitida reglamentariamente, será castigado con la pena de prisión de tres a seis meses o con la de multa de seis a doce meses o con la de trabajos en beneficio de la comunidad de treinta y uno a noventa días, y, en cualquier caso, con la de privación del derecho a conducir vehículos a motor y ciclomotores por tiempo superior a uno y hasta cuatro años.

2. Con las mismas penas será castigado el que condujere un vehículo de motor o ciclomotor bajo la influencia de drogas tóxicas, estupefacientes, sustancias psicotrópicas o de bebidas alcohólicas. En todo caso será condenado con dichas penas el que condujere con una tasa de alcohol en aire espirado superior a 0,60 miligramos por litro o con una tasa de alcohol en sangre superior a 1,2 gramos por litro.»
} 
cohol necesaria para que la conducción bajo ingesta alcohólica sea considerada típica. De forma que reiteradamente se ha determinado que son dos los elementos que requiere la conducta antijurídica: uno objetivo, consistente en el grado de impregnación alcohólica que padece el sujeto activo, y otro subjetivo, que se refiere a la influencia que tal grado de impregnación determine en la conducción. Ahora bien, la interpretación de esta influencia en la conducción ha resultado controvertida, ya que la misma actualmente no tiene por qué exteriorizarse en una flagrante infracción de las normas de tráfico, lo que sería constitutivo de un delito de peligro concreto, o más allá, en la producción de un resultado lesivo, esto es, en un delito de resultado, sino que basta que la conducción se realice con ese nivel etílico para que se entienda la misma constitutiva de un delito de peligro abstracto.

Por parte de la jurisprudencia de manera insistente también se recuerda que son dos los elementos que caracterizan este delito: el objetivo determinado por grado de impregnación alcohólica que padece el sujeto activo, y el subjetivo por la influencia que tal grado de alcohol provoca en la conducción. Aún así, también se especifica que este es un delito de mera actividad y por lo tanto, la sola creación de peligro abstracto ya ha de resultar punible ${ }^{2}$.

$\mathrm{Al}$ respecto, resulta muy aclaratoria la Circular de la Fiscalía General del Estado núm. 10/2011 de 17 de noviembre sobre Criterios para la Unidad de Actuación Especializada del Ministerio Fiscal en Materia de Seguridad Vial al resumirse en su texto ${ }^{3}$ que el delito del artículo $379.2 \mathrm{CP}$ inciso 2 . $^{\circ}$ es sin duda una infracción penal de peligro abstracto que conlleva que no sea preciso probar la influencia de la tasa de alcohol en la conducción, lo que se desprende, justifica,

2 De las resoluciones más recientes en este sentido la STS núm. 214/2010 de 12 de marzo (RJ 2010/2418) que determina que, «la influencia no tiene por qué exteriorizarse en una flagrante infracción de las normas de tráfico visible e inmediata (delito de peligro concreto), apreciada por el agente actuante, o en la producción de un resultado lesivo (delito de resultado), sino que basta el delito de peligro «in abstracto» practicándose, en su caso, la correspondiente prueba de detección alcohólica, y apreciándose por los agentes los signos externos de donde puede deducirse después (mediante prueba indirecta) ese grado de influencia en la conducción»- Fundamento Jurídico Segundo.

Por su interés, véase también la STS núm. 1061/2001 de 1 junio (RJ 2001\4594) donde se afirma que, «la sentencia impugnada declara unos hechos probados subsumibles en el artículo 379 del Código Penal, delito de peligro abstracto, por lo tanto de mera actividad, que no requiere un resultado con el que establecer el nexo causal con la acción. Basta la realización de la conducta típica, esto es, la conducción de un vehículo a motor bajo la influencia de bebidas alcohólicas, creando una situación de peligro.»Fundamento de Derecho Segundo.

3 Véase pp. 26 a 29 de la citada Circular. 
de la expresión en todo $\mathrm{caso}^{4}$, frente al tipo anterior subsistente en el artículo 379.2 inciso $1 .^{\circ}$ en el que sí son necesarios otros medios de prueba para constatar el requisito de que la conducción se realice bajo la influencia de determinadas sustancias. Por lo que en definitiva, constatada la conducción con la tasa legalmente establecida es innecesaria la concurrencia de maniobras irregulares o signos externos de embriaguez para que se realice la acción típica recogida en el inciso $2 .^{\circ}$ artículo 379.2 .

Entonces el tipo penal exige la constatación del influjo etílico como elemento perturbador del bien jurídico protegido que es la seguridad del tráfico, y la constatación de este elemento basta para la perfección del delito. De manera que la doctrina se decanta mayormente por la determinación de este delito como un delito de peligro abstracto $^{5}$ lo que supone claramente un adelantamiento de las barreras de protección penal ${ }^{6}$, si bien, hay un sector que matiza que debe de exigirse un peligro real aunque genérico de los sujetos implicados en el tráfico ${ }^{7}$, o sea, un peligro abstracto pero real para los bienes jurídicos vida e integridad de los intervinientes en el tráfico ${ }^{8}$, o dicho de otro modo, que se ponga en peligro abstracto los bienes implicados en el tráfico de vehículos y que la afectación de la seguridad del tráfico tenga una intensidad suficiente ${ }^{9}$.

Estas versiones acerca de la naturaleza del delito están íntimamente relacionadas con el objeto de tutela. Así, hay quien por un lado reconoce en este delito un bien tutelado intermedio en cuanto a que el interés último de protección es la vida, integridad física o

4 Artículo 379.2:

"Con las mismas penas será castigado el que condujere un vehículo de motor o ciclomotor bajo la influencia de drogas tóxicas, estupefacientes, sustancias psicotrópicas o de bebidas alcohólicas. En todo caso será condenado con dichas penas el que condujere con una tasa de alcohol en aire espirado superior a 0,60 miligramos por litro o con una tasa de alcohol en sangre superior a 1,2 gramos por litro.»

5 A modo de muestra véase, MONTANER FERNÁNDEZ, R., Delitos contra la Seguridad Vial, en SILVA SÁNCHEZ, J.M., (Dir.), Lecciones de Derecho Penal. Parte Especial, Ed Atelier, Barcelona, 2011, p. 289.

6 TAMARIT SUMILlA, J.M., De los Delitos contra la Seguridad del Tráfico, en Quintero Olivares, G., Comentarios a la Parte Especial del Derecho Penal, Ed. Aranzadi, Navarra, 1996, p. 1077.

7 SILVA SÁNCHEZ, J.M., Consideraciones sobre el Delito del artículo380 bis a) 1. ${ }^{\circ}$ del Código Penal, en VVAA, Derecho de la Circulación, Ed. Ministerio de Justicia, Madrid, 1993, p. 149.

8 DÍAZ REVORIO, J., La Prueba de Alcoholemia y sus Consecuencias en los ámbitos Administrativo-Sancionador y Penal, en Anuario Parlamento y Constitución, n. ${ }^{\circ}$ 4, 2000, p. 146.

9 MIR PUIG, S., Derecho Penal. Parte Especial, Ed. Tirant lo Blanch, Valencia, 1988, p. 427. 
patrimonio sobre el que el concepto de seguridad del tráfico opera con una función simplemente instrumental ${ }^{10}$, y por lo tanto, exigen que el alcohol haya influido en una conducción irregular para que pueda hablarse de una conducta peligrosa para la seguridad del tráfico ${ }^{11}$ con la constatación de un peligro real ${ }^{12}$, dado que la mayoría de los que defienden esta perspectiva establecen que el verdadero objeto de tutela son la vida e integridad física de los afectados por el tráfico viario ${ }^{13}$ por vincularse teleológicamente a intereses personales mediatamente protegidos ${ }^{14}$, llegando a definirlo como un delito de peligro concreto ${ }^{15}$. Mientras y en el otro extremo, otra corriente entiende que el delito encierra un bien jurídico autónomo de naturaleza colectiva con independencia de que la conducción implique o no riesgo para los bienes individuales ${ }^{16}$ y que se agota en el desvalor de la acción ${ }^{17}$, por lo que a todas luces lo tratan como un delito de peligro abstracto.

A mi criterio me decanto por la segunda opción ya que considero que realizar las matizaciones que aprecian los primeros puede provocar que para la perfección de delito se exija que no solo se supere la tasa de alcohol sino que además ésta se traduzca en una conducción peligrosa para los bienes individuales a los que hemos hecho mención. Es por lo que yo me decanto por la clasificación del delito como de peligro abstracto por ser típico el mero hecho de conducir con una tasa alcohólica superior a la establecida y por el riesgo que ésto comporta para el bien jurídico protegido que entiendo que es la

10 TAMARIT SUMILlA, J., Comentarios al Artículo 379, en Quintero Olivares, G. (Dir.), Comentarios al Nuevo Código Penal, Ed. Aranzadi, Navarra, 2005, p. 1678 y ss.

11 MUÑOZ CONDE, F., Derecho Penal. Parte Especial, Ed. Tirant 1 Blanch, Valencia, 2012, p. 591.

${ }_{12}$ GALLEGO SOLER, J.I., El Nuevo Delito de Conducción Bajo los Efectos del Alcohol y las Drogas, en Mir Puig, S. y Corcoy Bidasolo, M. (Dirs.), Seguridad Vial y Derecho Penal, Ed. Tirant lo Blanch, Valencia, 2008, p. 176.

13 ORTS BERENGUER, E., Delitos contra la Seguridad del Tráfico, en Vives Antón, T.S (Dir.), Comentarios al Código Penal de 1995, Ed. Tirant lo Blanch, Valencia, 1996, p. 640; CARMONA SALGADO, M.J., La Responsabilidad Penal en la Conducción Temeraria, en III Jornadas Nacionales de Derecho y Tráfico, Granada, 1988, p. 86.

14 CARMONA SALGADO, M.J., Delitos contra la Seguridad del Tráfico, en Cobo del Rosal, M. (Dir.), Compendio de Derecho Penal Español, Ed.Marcial Pons, Madrid, 2000, p. 1131.

15 CARPIO BRIZ, D.I., Creación de Grave Riesgo para la Seguridad en el Tráfico, en Mir Puig, S. y Corcoy Bidasolo, M. (Dirs.), Seguridad Vial y Derecho Penal, Ed. Tirant lo Blanch, Valencia, 2008, PÁG.214.

16 CALDERÓN CEREZO, A. y Choclán Montalvo, J.A., Código Penal Comentado, Ed. Deusto, Barcelona, 2004, p. 831.

17 MAQUEDA ABREU, M.L., La Idea de Peligro en el Derecho Penal Moderno, en Actualidad Penal, junio, 1994, p. 4867. 
seguridad vial, y es éste el motivo por el que secundo que el delito se cometa por el sólo hecho de conducir rebasando esa tasa de alcohol establecida ${ }^{18}$, sin la necesidad de ninguna exigencia más añadida tal como la especial proximidad, inminencia o concreción del riesgo -que establecen otros autores ${ }^{19}$-, ya que entiendo que es precisamente la peligrosidad de la conducción con un nivel de alcohol superior al permitido lo que lleva al legislador a criminalizar esta conducta ${ }^{20}$. No encuentro preciso acreditar la influencia en la conducción de esa tasa porque a mi juicio es innegable que por encima del nivel establecido existe una disminución de reflejos, de capacidad sensorial, de atención y en definitiva, un mayor riesgo en la conducción que no debería requerir de la provocación de un peligro concreto para resultar punible ${ }^{21}$. Y es que a mi juicio este delito se caracteriza por la rapidez con la que se suceden los hechos, lo que conlleva que el esperar a que el peligro se concrete en un riesgo determinado supondría situar muy alto el umbral de la conducción que puede resultar impune y que ello provoque que cuando ese peligro se llegue a concretar sea no sea en un riesgo más concreto, sino por desgracia en un delito de resultado lesivo que pudo evitarse fácilmente. Por lo que para mí la conducción bajo ingesta alcohólica según los límites establecidos es a todas luces una actividad de riesgo merecedora de reproche penal sin necesidad entiendo, de una mayor concreción. Además esta es la interpretación que considero más acorde con la literalidad del precepto penal -inciso $2 .^{\circ}$ art.379.2 C.P- y justifico sin lugar a dudas la intención preventiva del legislador aquí recogida.

En cambio, como digo, hay autores que apuntan que debe abandonarse la tendencia hacia la objetivación ${ }^{22}$ y se muestran contrarios a la criminalización por vía penal de todas las conductas que supongan conducción con tasas máximas a las permitidas ${ }^{23}$, por lo que no

18 Así reconocido por autores como MUÑOZ MEDINA, M.M., La Potestad Sancionadora de la Administración en Matera de Tráfico, Ed. Colex, Madrid, 2012, p. 129.

19 Véase por su argumentación, VARGAS CABRERA, B., El Delito de Conducción Bajo la Influencia de Bebidas Alcohólicas y Drogas Tóxicas del artículo 379 C.P., en Estudios de Derecho Judicial, núm.114, 2007, p. 142.

20 SOTO NIETO, F., Conducción Bajo los Efectos de Drogas o Bebidas Alcohólicas, en La Ley, núm. 6167, 2005, p. 1.

21 Acerca de la incidencia de los distintos efectos del alcohol véase, BARQUÍN SANZ, J., Seguridad en la Conducción tras Consumo Moderado de Bebidas Alcohólicas, en Morillas Cueva, L. (Coord.), Delincuencia en Materia de Tráfico y Seguridad Vial, Ed. Dykinson, Madrid, 2007.

22 DÍAZ REVORIO, J., La Prueba de Alcoholemia y sus Consecuencias en los Ámbitos Administrativo-Sancionador y Penal: análisis desde la perspectiva constitucional», en Anuario Parlamento y Constitución, núm. 14, 2000, p. 152.

23 Idem., p. 164. 
sólo requieren la superación de una tasa sino que la misma influya en la conducción ${ }^{24}$. Esta corriente se apoya en el argumento de que si así fuera, nos encontraríamos ante una prueba legal tasada que chocaría de plano con el principio de libre valoración de la prueba y que haría prácticamente innecesario el proceso ${ }^{25}$. Más allá, incluso hay quien apunta que estamos ante un delito de peligro concreto en el que se ha de verificar y exteriorizarse la influencia del alcohol en la conducción del sujeto a través de parámetros indiciarios explícitos suficientes que permitan validar no sólo la ingesta de alcohol, sino también la citada incidencia en la capacidad del sujeto para conducir y la potencialidad lesiva de su acción ${ }^{26}$.

Si estamos conformes con que la intervención del derecho penal es necesaria cuando lo exija la protección del bien jurídico ${ }^{27}$, a mi entender la exigencia de que el alcohol cause efecto en la conducción para la realización del tipo conllevaría una gran inseguridad jurídica, aparejada al hecho además, de que la valoración de estos efectos es claramente subjetiva, de manera que a tenor del delito del que se trata y del bien jurídico que éste protege entiendo que la objetivación que realiza el legislador es necesaria, ya que consigue ser un criterio fijo no sujeto a diferencias interpretativas y que de manera nítida distingue la que pudiéramos considerar una conducción punible de la que no. Es cierto que ante esta tesis tendremos que soportar la crítica que define a este delito como un delito de concepción puramente formalista ${ }^{28}$, pero insisto que este carácter formal del tipo es más bien un elemento garantista que asegura que la interpretación de la conducta punible se realiza a todas luces con un criterio objetivo. Incluso la exigencia de que el peligro abstracto suponga un peligro real para el bien tutelado ${ }^{29}$ me parece demasiado inespecífica por la dificultad que entonces va a tener el juzgador para valorar ese

24 Idem., p. 165.

25 GONZÂLEZ RUS, J.J., El Delito de Conducción Bajo la Influencia de Bebidas Alcohólicas y la Prueba de Alcoholemia en la Jurisprudencia Constitucional, en Revista de la Facultad de Derecho de la Universidad de Granada, núm. 15, 1998, p. 56.

26 MORILLAS FERNÁNDEZ, D.L., La Influencia Directa del Alcohol como Elemento Integrante del Artículo 379 del Código Penal, en Morillas Cueva, L. (Coord.), Delincuencia en Materia de Tráfico y Seguridad Vial, Ed. Dykinson, Madrid, 2007, p. 184.

27 MIR PUIG, S., Bien Jurídico y Bien Jurídico Penal, en Estudios Penales y Criminológicos, XIV, Ed. Universidad de Santiago de Compostela, Santiago de Compostela, 1991, p. 203.

28 GUTIÉRREZ RODRÍGUEZ, M., Excesos de Velocidad e Intoxicaciones Punibles, en Gutiérrez Rodríguez, M. (Coord.), Protección Penal de la Seguridad Vial, Ed. Tirant lo Blanch, Valencia, 2009,, p. 86.

${ }_{29}$ LASCURAÍN SÁNCHEZ, J.A., en Rodríguez Mourullo, G. (Ed.), Comentarios al Código Penal, Ed. Civitas, Madrid, 1997, p. 1040. 
riesgo real y por la diferencias de criterio que pudieran surgir según la valoración subjetiva que el material probatorio pueda inspirar en cada caso $^{30}$.

No podemos negar que los efectos del alcohol como pueden ser la descoordinación motriz, el olor a alcohol, o la pastosidad del habla, no dejan de ser indicios que no pueden establecerse de forma unitaria permitiendo emitir un juicio de valor sobre la incidencia directa del alcohol sobre la conducción ${ }^{31}$, algo que considero es una valoración del todo subjetiva desprovista de la determinación y objetividad necesaria que ha de requerir el tipo penal. En cambio la tasa establecida ofrece un criterio de penalización objetivo que aunque también está expuesta al criterio médico legal ${ }^{32}$ que establece qué valores merecen de la intervención penal -sobre lo que no podemos detenernos en este momento ${ }^{33}$ - al menos la tasa actualmente vigente $-0,60$ miligramos por litro en aire espirado o 1,2 gramos por litro en sangre- es ya un criterio determinado que a mi juicio aporta una gran seguridad jurídica al proceso.

Por lo anterior la jurisprudencia actual de manera mayoritaria se refiere a que pese a que son dos son los elementos que caracterizan el tipo delictivo del artículo 379.2 inciso segundo -el objetivo consistente en el grado de impregnación alcohólica que padece el sujeto, y otro subjetivo que se refiere a la influencia de tal grado en la conducción- este delito es un delito de peligro abstracto donde la sola conducción sobre la tasa determinada ya es punible. Aún así, este es un criterio mayoritario pero no unánime ya que también encontramos numerosas resoluciones que sí que exigen que este peligro conlleve un riesgo real y que se corrobore la influencia de la ingesta de alcohol en la conducción para considerar la conducta antijurídica ${ }^{34}$, por

30 Diferencias ya aludidas en la Memoria de la Fiscalía General del Estado del año 2005, p. 533.

31 MORILLAS FERNÁNDEZ, D.L., La Influencia Directa del Alcohol como Elemento Integrante del Artículo 379 del Código Penal, cit., p. 191.

32 Por su ilustración véase VILLANUEVA CAÑADAS, E., Estudio Toxicológico y Médico-Legal del Alcohol, en Gisbert Calabuig, J.A., Medicina Legal y Toxicología, Ed. Elsevier Masson, Barcelona, 1997, p. 662.

33 Para profundizar en el valor de la tasa de alcohol y sus distintos efectos en el conductor, véase por su interés BARQUÍN SANZ, J. y LUNA DEL CASTILLO, J.D, Seguridad en la Conducción tras Consumo Moderado de Bebidas Alcohólicas, cit., pp. 439 a 503.

34 Así, es muy común encontrar Sentencias que determinan que, «la jurisprudencia ha declarado también que, para que proceda la aplicación del artículo 379 del Código Penal, no es necesario demostrar la producción de un "peligro concreto" ni, por supuesto, ningún resultado lesivo, como demandan otros tipos penales, por cuanto el tipo aquí examinado exige únicamente la existencia de un "peligro abstracto" que, en todo 
la necesidad, según se argumenta, de que se dé una conducción anómala, y con esto, un riesgo real y grave para la seguridad del tráfico para que se active la intervención penal ${ }^{35}$.

Por mi parte insisto en la idoneidad de definir el delito como de peligro abstracto sin ninguna concreción más añadida, lo que provocará que se perfeccione ya por la mera conducción con una tasa de alcohol superior a la legalmente establecida y sin la necesidad de valorar los índices de detección alcohólica conjuntamente con otras pruebas $^{36}$, y de que la impregnación alcohólica se tenga en consideración junto con todo un cúmulo de circunstancias concominantes al supuesto particular ${ }^{37}$. Para mí este último requisito no goza de seguridad jurídica por ser la interpretación de los efectos en la conducción un criterio subjetivo que puede conducir al riesgo de que quede impune aquella conducción que pese a superar la tasa de alcohol establecida, no se presenta en ninguna conducción anómala, pero que indudablemente sí que provoca un riesgo para la seguridad vial ya que no considero cuestionable que la tasa objetivada produce una merma de la capacidad del conductor de realizar una conducción segura. Y es por lo que me adhiero por completo al criterio expuesto en Sentencia de la Audiencia Provincial de Barcelona núm. 786/2011 de 30 junio (JUR 2011\319922) que se refiere a que "dicho tipo penal -refiriéndose al delito de estudio- se configura desde el punto de vista dogmático como un delito de peligro abstracto en sentido puro, de forma que el legislador establece el reproche penal con independencia de la creación de ninguna situación de riesgo concreta, considerando dicha conducta peligrosa per se y merecedora de reproche. »-Fundamento de Derecho Tercero. También la STS de 15 de abril de 2002 se muestra tajante en este sentido cuando define "peligro abstracto como toda conducción previa ingesta de alcohol u otras sustancias típicas aún cuando no se infrinjan las normas de tráfico ni se genere peligro alguno para la seguridad del mismo»- Fundamento Jurídico Segundo.

A tenor de lo anterior tenemos que añadir que ya la Instrucción núm. 3/2006 de 3 de julio sobre Criterios de Actuación del Ministerio Fiscal para una Efectiva Persecución de los Ilícitos Penales relacio-

caso, ha de ser real y no meramente presunto (v. SS. de 19 mayo 1982 [RJ 1982, 2689], 7 julio 1989 [RJ 1989, 6125] y 5 marzo 1992 [RJ 1992, 1788], entre otras).»- Fundamento de Derecho Segundo de la STS núm. 1/2002 de 22 marzo (RJ 2002\4207).

35 GÓMEZ PAVÓN, P., El Delito de Conducción Bajo la Influencia de Bebidas Alcohólicas, Drogas Tóxicas y Estupefacientes, Ed. Bosch, Barcelona, 1998, p. 117.

36 MUÑOZ CONDE, F., Derecho Penal. Parte Especial, cit., p. 682.

37 CARMONA SALGADO, C., Delitos contra la Seguridad del Tráfico, en Cobo del Rosal, M. (Dir.), Derecho Penal Español. Parte Especial, Ed. Dykinson, Madrid, 2005 , p. 799. 
nados con la Circulación de Vehículos a Motor había resumido la controversia interpretativa planteada y que apuntaba a que mientras que para algunos era bastante la demostración indiciaria de que la ingestión alcohólica había afectado a la capacidad psicofísica del conductor a partir de los signos externos de afectación etílica que se manifestaran en el mismo, para otros era preciso que dicha influencia se tradujera en una conducción anómala e incluso, para una tercera opinión, no resultaba suficiente la coexistencia de conducción irregular y la presencia de signos externos de embriaguez, sino que además entre éstos habría de aparecer la afectación de la capacidad de expresión o de ambulación del sujeto ${ }^{38}$. De forma que como respuesta a esta controversia y con la intención de realizar una unificación de criterio en la mencionada Instrucción la Fiscalía General del Estado se resolvía que cuando el grado de impregnación alcohólica fuera superior a 1,2 gr. de alcohol por 1.000 c.c de sangre o su equivalente de 0,60 mg. de alcohol en litro de aire espirado podría estimarse que esa elevada hemoconcentración etílica evidenciaba por sí misma una merma de las facultades psicofísicas exigibles para la conducción segura de un vehículo a motor en cualquier conductor, con el consiguiente riesgo para la seguridad vial ${ }^{39}$. Interpretación ésta que como ya he expuesto secundo ya que en definitiva, estoy en contra de la opinión de que para la traba del riesgo producido por la conducción habiendo ingerido bebidas alcohólicas basta el derecho administrativo sancionador ${ }^{40}$, ya que sobre esta tasa objetivada entiendo justificada la intervención penal.

Para mí la conducción bajo la tasa objetivada de alcohol satisface tanto el elemento formal como el material de la antijuricidad, y ello porque entiendo que con una conducción de esas características ya se está perturbando el bien tutelado que interpreto es la seguridad del tráfico. Más aún, en términos de política criminal, la creación de un peligro real que requieren otros autores ${ }^{41}$ no creo que garantice una intervención estatal eficaz a este tipo de conductas en los términos que requiere actualmente nuestra sociedad. Incluso en el caso de decantarnos por la interpretación que exige una manifestación externa del alcohol en la conducción, cabría preguntarse qué signo o

38 Páginas 14 y 15 de la Instrucción núm. 3/2006.

39 Idem., p. 16.

40 Magaldi Paternostro, M.J., El Tipo del Artículo 380 del Código Penal: Una Propuesta Interpretativa, en De Vicente Martínez, R. (Dir), Derecho Penal y Seguridad Vial, Ed. Consejo General del Poder Judicial, Madrid, 2007, p. 204.

41 Por citar un ejemplo y en base a su importancia véase, MAGALDI PATERNostro, M.J., El Tipo del Artículo 380 del Código Penal: Una Propuesta Interpretativa, cit., p. 206. 
signos externos van a ser los necesarios para realizar el tipo ${ }^{42}$, ¿bastará cualquier infracción de la seguridad del tráfico? ¿será necesario un nivel de gravedad en la infracción? más aún, cuando es crítica generalizada la subjetividad interpretativa de cada uno de esos signos externos ${ }^{43}$ y que son muchos, a los que me añado, los que cuestionan la eficacia probatoria de la diligencia de sintomatología del atestado policial para acreditar realmente la influencia de la ingesta en la conducción ${ }^{44}$.

A mi juicio la necesidad de que se den estos signos para que se entienda penalmente relevante la conducta nos conduciría a una grave inseguridad jurídica por la falta de objetivación y determinación de cuáles serían estos signos en la norma penal. En definitiva, la sola posibilidad de que se pueda absolver al conductor que pese a contar con una tasa superior a la establecida conduzca de forma correcta ${ }^{45}$ en un evidente desprecio a la vida de los demás, es un riesgo que no puede permitirse nuestro sistema penal.

Esta valoración es apuntada por algunos autores que también justifican esta intervención penal por la necesidad de la sociedad actual de evitar el hecho que da lugar al riesgo ${ }^{46}$, sin que a mi modo de ver esta política pueda tildarse de conculcar el principio de mínima intervención por la solvencia e importancia que desprende el bien tutelado. Por todo lo cual para mí queda suficientemente acreditado el carácter de peligro abstracto del delito que comentamos, así como considero necesario que la jurisprudencia se esfuerce en unificar su criterio en este sentido, ya que resulta incomprensible que pese a las determinaciones objetivas recogidas en el inciso segundo del artículo 379.2, y a la interpretación que del mismo realiza incluso la Fiscalía General del Estado, aún encontremos Sentencias que de manera reciente sigan exigiendo la constatación externa de los efectos del nivel etílico del conductor para entender realizado el tipo penal, cuando resulta evidente, y a la vez necesario a efectos de política cri-

42 SILVA SÁNCHEZ, J.M., Consideraciones sobre el Delito..., cit., p. 32.

43 OCHOA CASTELEIRO, A., Los Delitos contra la Seguridad del Tráfico del Artículo 379 del Código Penal desde el Punto de Vista Médico-Legal, en Revista Vasca de Derecho Procesal y Arbitraje, núm. 1, 2006, p. 67.

${ }_{44}$ GALLEGO SOLER, J.I., El Nuevo Delito de Conducción Bajo los Efectos del Alcohol y las Drogas, en Mir Puig, S. y Corcoy Bidasolo, M. (Dirs.), Seguridad Vial y Derecho Penal, Ed. Tirant lo Blanch, Valencia, 2008, p. 167.

45 GUTIÉRREZ RODRÍGUEZ, M., Excesos de Velocidad e Intoxicaciones Punibles, cit., p. 84.

46 VILlalBA CARRASQUILLA, F.J., El Endurecimiento de las Penas en lo Delitos de Tráfico como Medida de Mejora de la Siniestralidad, en Mir Puig, S. y Corcoy Bidasolo, M. (Dirs.), Seguridad Vial y Derecho Penal, Ed. Tirant lo Blanch, Valencia, 2008 , p. 329. 
minal, el que sea suficiente la realización del elemento objetivo del delito para que la conducta pueda resultar punible. Estas diferencias de criterio entre los tribunales y su falta de adhesión al criterio objetivo de interpretación que propone la Fiscalía ocasionan una evidente inseguridad jurídica para los propios encausados cuya condena va a depender de la interpretación que el juzgador realice de los signos externos de su conducción etílica.

Además la Fiscalía General según la citada Circular núm. 10/2011 de 17 de noviembre considera que si las pruebas de alcohol detectasen el consumo pero arrojasen un resultado inferior a la tasa objetivada pero por encima de la tasa de 0,80 gr. de alcohol por 1.000 c.c. de sangre o 0`4 mg de alcohol en aire espirado, se ejercerá normalmente la acción penal por delito contra la seguridad del tráfico cuando concurran circunstancias tales como la existencia de síntomas de embriaguez en el conductor, la conducción peligrosa o descuidada, o el haber provocado un accidente.

Y por último, también determina que si la tasa de alcohol es inferior a 0,80 gr. de alcohol por 1.000 c.c. de sangre o 0,40 mg. de alcohol por litro de aire espirado, los Sres. Fiscales no ejercitarán la acción penal por delito del artículo $379 \mathrm{CP}$, derivando los hechos a la vía sancionadora administrativa, salvo en aquellos casos singulares en que por concurrir circunstancias que evidencien una efectiva afectación de la capacidad psicofísica para la conducción del imputado existan indicios bastantes de la comisión de dicho delito ${ }^{47}$.

Como vemos, para el caso que la tasa tenga un resultado inferior a la tasa objetivada pero por encima de la tasa de $0,80 \mathrm{gr}$. de alcohol por 1.000 c.c. de sangre o 0'4 mg de alcohol en aire espirado, sí que van a adquirir relevancia los signos externos del conductor, signos que en la mayoría de los casos dependerán de la valoración subjetiva de los testigos, entre ellos los mismos agentes de la autoridad intervinientes. De manera que estos signos externos que cuando la tasa supera la objetivada en el inciso segundo del artículo 279.2 tienen una validez calificada de secundaria ${ }^{48}$, en el caso de que no se supere la misma van a adquirir una relevancia probatoria esencial en el proceso. Además, para el supuesto de que ni siquiera llegara a alcanzarse la tasa de 0,80 gr. de alcohol por 1.000 c.c. de sangre ó 0,40 mg. de alcohol por litro de aire espirado, la conducción sólo tendrá relevancia penal si en efecto este grado de alcohol se aprecia

47 Véase pp. 26 a 29 de la citada Circular.

48 GUTIERREZ RODRÍGUEZ, M., Excesos de Velocidad e Intoxicaciones Punibles, cit., p. 96. 
en una evidente conducción irregular, y de nuevo ésto comportará una valoración subjetiva para apreciar el hecho. Y ello porque de no superarse la tasa objetivada en el inciso segundo se podría apreciar el delito según los términos del inciso primero del artículo 379.2 ${ }^{49}$.

$\mathrm{Y}$ es por este criterio subjetivo en su enjuiciamiento por lo que encontramos distintas resoluciones en nuestra jurisprudencia que ante tasas de alcohol inferiores a la objetivada -de 1,2 gr. de alcohol por 1.000 c.c de sangre o su equivalente de $0,60 \mathrm{mg}$. de alcohol en litro de aire espirado- aprecian con diferencia de criterio la condena o absolución del acusado según el grado de afección que se interprete tenga el conductor en la conducción. De esta forma, al presentar el autor una conducción irregular encontramos Sentencias que condenan con una tasa de alcohol de 0,43 $\mathrm{mg}$ de alcohol por litro de aire espirado ${ }^{50}$, o incluso con menos valor, si se acreditan suficientes signos de afectación de la conducción ${ }^{51}$.

49 "Con las mismas penas será castigado el que condujere un vehículo de motor o ciclomotor bajo la influencia de drogas tóxicas, estupefacientes, sustancias psicotrópicas o de bebidas alcohólicas».

50 Así, la Sentencia de la Audiencia Provincial de Guadalajara núm. 151/2012 de 12 diciembre (JUR 2013\8093) establece condena para un supesto con una tasa de alcohol de 0,43 mg de alcohol por litro de aire espirado y argumenta que «la prueba de detección alcohólica practicada que arroja un resultado de 0,43 $\mathrm{mg}$ de alcohol por litro. En lo que concierne a la influencia en la conducción de dicha ingesta alcohólica, la misma se razona en la sentencia apelada con argumentos que al no haber sido eficazmente combatidos en el recurso de apelación permanecen incólumes en esta alzada, a saber, que el acusado presentaba ojos brillantes, rostro congestionado, aliento a alcohol, habla pastosa, repetición de expresiones y deambulación vacilante, e igualmente que cambió súbitamente de sentido atravesando la línea continua de la calzada por la que circulaba, signos los dichos y comportamiento que evidencian la influencia en la conducción de la previa ingestión de alcohol por parte del acusado Debemos recordar al respecto que la examinada influencia no sólo se puede colegir de actos directos y objetivos patentizados y traídos al juicio por los testigos (zigzagueo, conducción peligrosa, infracciones administrativas de tráfico), sino que también se colige de la descripción de un estado físico de tal entidad que resulte incompatible con unos mínimos patrones de autocontrol, de un grado de impregnación alcohólica igualmente incompatible con una conducción ordinaria o, finalmente, de las propias manifestaciones del sujeto activo en cuestión o de su comportamiento con la fuerza actuante.»-Fundamento de Derecho Segundo.

51 Por mostrar un caso actual, véase la STS núm. 706/2012 de 24 de septiembre (RJ 2012 19077 ) que condena el caso de un conductor que presentó la tasa de 0,38 mg. de alcohol en litro de aire espirado y que atropelló a varias persona y argumenta, "Que la tasa sea insuficiente para generar de forma automática responsabilidad penal según el texto del artículo 379 vigente desde la Ley Orgánica 15/2007 (RCL 2007, 2180 ) es una aseveración compartible: se fija la tasa objetivada en 0,60. Eso no excluye que con tasas inferiores se pueda llegar a una condena por el delito del artículo 379, si se demuestra la repercusión en la conducción. Antes de esa reforma una praxis muy extendida, causa y fruto simultáneamente de la Instrucción 3/2006 (JUR 2006, 194921) de la Fiscalía General del Estado, venía recogiendo esas orientaciones. Con la eficacia interna de esos documentos se señalaba por la Fiscalía General que a partir de una tasa 
En cambio, también hallamos resoluciones absolutorias con tasas de $0,67^{52}, 0,57^{53}$ o $0,53^{54} \mathrm{mg}$ por litro de aire espirado, por citar varios

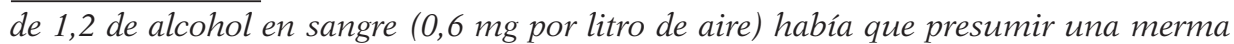
relevante de las facultades fueren cuales fueren las condiciones físicas del conductor y que por tanto los hechos podían ser subsumidos en el artículo 379, aunque no se hubiese detectado alguna maniobra o actitud expresiva de ese influjo (STS 1133/01 de 11 de junio (RJ 2003, 2460 ) ). Y -se continuaba diciendo-en los casos de tasas superiores a 0,80 (0,40 si nos referimos a litro de aire espirado) habría que valorar las circunstancias concurrentes (sintomas, comisión de infracciones circulatorias, conducción descuidada, provocación de algún accidente...) que demostrasen en caso que esa ingesta de alcohol había menoscabado de forma efectiva la capacidad para pilotar con seguridad un vehículo de motor.»-Fundamento de Derecho Primero; manifestando de esta manera el criterio de que pese a la existencia de una tasa inferior a la recogida en el precepto 379.2.2, también será posible la intervención penal dependiendo del grado de afección del autor.

52 Como la Sentencia de la Audiencia Provincial de Vizcaya núm. 90516/2012 de 15 octubre (JUR 2013\153547), que absuelve al autor con una tasa de 0,67 mg/l -primera medición-y de $0,53 \mathrm{mg} / \mathrm{l}$-segunda- por la valoración que se realiza por el juzgador acerca de la incidencia de esta tasa sobre su conducción. Así argumenta que, "En el presente caso la juez en el fundamento de derecho primero de la sentencia recurrida ha valorado la prueba y ha motivado el porqué de su convicción de que los hechos se produjeron tal como se narran en el factum de la sentencia recurrida, habiendo basado su convicción de que los hechos sucedieron tal como declara probados en el resultado de las pruebas de detección alcohólica practicadas al acusado que tal como consta al folio 6 fue a las 03.56 horas de $0,67 \mathrm{mg} / \mathrm{l}$ y a las 04.14 horas de 0,53 $\mathrm{mg} / \mathrm{l}$, los cuales por si solos, aun cuando se aplique el margen de error del 7,5\%, únicamente son indicativos de una ingesta de alcohol por el acusado pero no de la merma de sus facultades psicofísicas para conducir, y también se ha basado la Juez en que en las declaraciones efectuadas en el acto del juicio oral por los testigos agentes de la Ertzaintza n. ${ }^{\circ}$ 13316,4571, 1802, 7306 y 12338, éstos manifestaron que el acusado presentaba olor a alcohol, ojos rojos y habla pastosa, concluyendo la Juez que aunque el acusado no puede mantener el equilibrio por la ciática que padece, los agentes observaron síntomas inequívocos de la ingesta de bebidas alcohólicas tales como ojos rojos y olor a alcohol. Pues bien, estos sintomas de olor a alcohol, ojos rojos y habla pastoso no acreditan de manera inequívoca que las bebidas consumidas hubieran mermado las facultades psicofísicas del acusado necesarias para la conducción del vehículo y ello porque el olor a alcohol lo único que indica es la ingesta de bebidas alcohólicas pero no su cantidad ni una merma de las facultades psicofísicas del acusado y los ojos rojos y el habla pastosa no son síntomas inequívocos de la merma de la merma de las facultades psicofísicas por la ingesta de alcohol toda vez que pueden responder a muchas causas, máxime teniendo en cuenta en cuenta la hora en que ocurrieron los hechos, y en todo caso por si solos no son indicativos de una merma de las facultades necesarias para la conducción de un vehículo. Asimismo razona la juzgadora que otro dato acreditativo de la merma de facultades para conducir resulta de las manifestaciones de los testigos agentes de la Ertzaintza n. ${ }^{\circ} 18102$ y 7306 sobre la forma de conducir del acusado, ahora bien la forma de conducir el acusado si bien es irregular y puede ser constitutiva de infracción administrativa, sin embargo, no denota una falta de control del vehículo por parte del acusado indicativa de una merma de facultades por la ingesta de bebidas alcohólicas. Por todo ello ha de concluirse que en el presente caso y al vista de los razonamientos efectuados por la Juzgadora no resulta suficientemente justificado que las bebidas ingeridas por el acusado hubieran mermado su facultades psicofísicas. En consecuencia procede estimar el motivo de impugnación y revocar la sentencia 
ejemplos, donde el juzgador entiende que estas tasas únicamente son indicativas de una ingesta de alcohol por parte del autor pero no de una merma de sus facultades psicofísicas para conducir. Y es que, resumidamente, el Alto Tribunal ha reiterado que «es un criterio jurisprudencial y forense consolidado, que la diferencia entre el ilícito administrativo y el penal, cuando se trata de conducción bajo ingesta alcohólica, radicaba entre otros aspectos, en el carácter meramente formal de la norma administrativa de superar una determinada ingesta alcohólica mediante las oportunas periciales, en tanto que el ilícito penal supera esa trasgresión formal para exigir la acreditación de un peligro real para la seguridad del tráfico, esto es, la influencia en las facultades psicofísicas necesarias para la conducción poniendo en peligro los bienes jurídicos protegidos en la norma»-Fundamento Jurídico Segundo de la STS núm. 867/2006 de 15 septiembre (RJ 2006\7350).

En referencia a esta interpretación es cierto que debemos de ser conscientes de que la relevancia penal de la infracción de nuestro estudio ha de interpretarse a la luz del Principio de Intervención Mí-

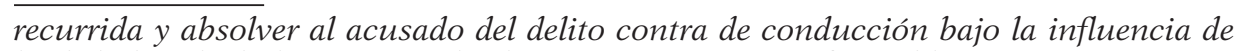
las bebidas alcohólicas, con todos los pronunciamientos favorables.»-Fundamento de Derecho Segundo.

53 Para citar una muestra, véase la Audiencia Provincial de Barcelona en Sentencia núm. 608/2012 de 21 de junio (JUR.2012/274202) absuelve al imputado que presentó o,60 mg por litro de aire espirado -primera medición- y 0,57 -segunda-, al entender que los signos que presentaba el conductor y esta tasa no tenían relevancia penal y eran más bien merecedores de una sanción administrativa. En el Fundamento de Derecho Primero el Juzgador argumenta, «Mas ello unido a la falta de suficiencia acreditativa de las manifestaciones del referido agente sobre la irregularidad de la conducción así como sobre su sintomatología, ello implica el que no puedan constituir prueba de cargo suficiente como para acreditar el tercer y último requisito preciso para la apreciación de la figura delictiva prevista en el artículo 379 CP, de una influencia alcohólica en la conducción por parte del sujeto activo y que constituye la creación del riego abstracto penalmente proscrito, sin que los hechos, en consecuencia, transciendan, a lo sumo, de una mera infracción administrativa».

54 Con igual criterio, la Sentencia de la Audiencia Provincial de Málaga núm. 450/2012 de 23 julio (JUR 2013\136799) absuelve al conductor que dio como resultado una concentración de alcohol de 0'53 mg por litro de aire espirado -primera medida- y de 0'54 mg-segunda-, porque refiere que, "en el caso enjuiciado en que el apelante presentaba una deambulación normal y no consta cometiera irregularidad alguna con ocasión de la conducción del vehículo de motor que guiaba, no han concurrido los requisitos necesarios para reputar la infracción cometida por el mismo al conducir el vehículo de autos con un grado de alcoholemia superior al normativamente permitido, como infracción susceptible de integrar el delito contra la seguridad vial del artículo 379-2 del Código Penal por el que ha resultado condenado, siendo por ello que procede la estimación del recurso planteado, y ello sin perjuicio de la responsabilidad administrativa que le resultare derivable por los hechos enjuiciados.»- Fundamento de Derecho Primero. 
nima ${ }^{55}$, y que los preceptos penales de análisis han de quedar reservados para aquellos riesgos de mayor intensidad para prevenir las conductas que se estiman de mayor peligrosidad en la conducción ${ }^{56}$, lo que ha conllevado que haya autores que encuentren que los delitos de nuestro comentario no dejen de ser muestra de un nuevo derecho penal del enemigo ${ }^{57}$ y que habría de tenerse en cuenta que el injusto de la acción penalmente relevante tiene que ser más grave que la más grave de las infracciones administrativas ${ }^{58}$. Pero acerca de este extremo yo quisiera volver a insistir en el riesgo inherente a las diferencias valorativas del elemento subjetivo del tipo que se refiere a la apreciación de la conducción irregular del autor, y es éste el motivo por el que personalmente quisiera proponer que lege ferenda se planteara la posibilidad de dotar de un mayor contenido objetivo al delito de estudio también a la hora de concretar cuándo va a tener relevancia penal la conducción irregular por debajo de la tasa etílica establecida en el inciso segundo, más aún cuando sabemos que con idénticas tasas la influencia en el conductor puede ser diferente dependiendo de las características personales de cada sujeto $^{59}$. A este respecto hay autores que apuntan que la influencia en la conducción ha de detectarse cuando el sujeto sufra una afectación de las facultades que le impida conducir su vehículo con seguridad $^{60}$, aunque a mi criterio este último es un criterio impreciso y ambiguo que sin duda va a conllevar diferencias interpretativas en nuestra jurisprudencia.

$\mathrm{Y}$ es que, ante el delito que comentamos y según las graves consecuencias del mismo, en mi opinión resulta necesario potenciar el elemento normativo del tipo penal de manera que se establezcan datos objetivos que sin necesidad de una valoración subjetiva y externa de la conducción y del estado del sujeto, consigan determinar de manera indubitada su carácter típico o no. Y a pesar de ser

55 Según el principio de intervención mínima, el Derecho Penal debe tener carácter de última ratio por parte del Estado para la protección de los bienes jurídicos y sólo para los más importantes frente a los ataques más graves, pues de lo contrario el recurso a la sanción penal resultaría innecesario y desproporcionado.

56 TERRADILlOS BASOCO, J.M., Peligro Abstracto y Garantías Penales, en Quintero olivares, G. y Morales Prats, F., (Coords.), El Nuevo Derecho Penal Español. Estudios Penales en Memoria del Profesor José Manuel Valle Muñiz, Ed. Aranzadi, Pamplona, 2001, p. 798.

57 MAgaldi Paternostro, M.J., El Tipo del Artículo 380 del Código Penal: Una Propuesta Interpretativa, cit., p. 194.

58 Idem., p. 201.

59 SILVA SÁNCHEZ, J.M., Consideraciones sobre el Delito..., cit., p. 157.

60 RODRÍGUEZ FERNÁNDEZ, I., La Conducción Bajo la Influencia de Bebidas Alcohólicas, Drogas Tóxicas, Estupefacientes y Sustancias Psicotrópicas, Ed. Comares, Granada, 2006, p. 115. 
cierto que el intervencionismo estatal no puede en ningún caso, por necesario que sea, avasallar la dignidad y seguridad de los ciudadanos ${ }^{61}$, así como puede ser que con esta técnica se esté realizando una baremación del peligro en base a consideraciones médico-científicas ${ }^{62}$, no se puede cuestionar que la ingesta alcohólica provoca cuanto menos, un pilotaje anómalo y una negativa repercusión en la seguridad vial ${ }^{63}$ que a mi entender es claramente merecedora de reproche penal.

Por último, la vía sancionadora administrativa es la recogida en el artículo 65.5.c) del Real Decreto Legislativo 339/1990, de 2 de marzo por el que se aprueba el Texto Articulado de la Ley sobre Tráfico, Circulación de Vehículos a Motor y Seguridad Vial y establece que cuando no sea constitutiva de delito es considerada infracción muy grave, "la conducción por las vías objeto de esta Ley habiendo ingerido bebidas alcohólicas con tasas superiores a las que reglamentariamente se establezcan, y en todo caso, la conducción bajo los efectos de estupefacientes, psicotrópicos, estimulantes y cualquier otra sustancia de efectos análogos». De forma que son muchas las cuestiones que surgen entre la separación entre el ilícito penal y el administrativo ante un supuesto de conducción bajo ingesta alcohólica, y por ello son numerosas las Sentencias que tratan este asunto por la posible conculcación del Principio Non Bis in Idem ${ }^{64}$, así como por la dificultad para diferenciar en ocasiones el contenido del injusto penal con los ilícitos administrativos ${ }^{65}$. Para ello, resulta unánime la alusión a la necesidad de que por debajo de la tasa establecida en el

61 MORILLAS CUEVA, L., Derecho Penal Parte General. Fundamentos Conceptuales y Metodológicos del Derecho Penal, Ed. Dykinson, Madrid, 2004, p. 113.

${ }_{62}$ La determinación de esta tasa punible ha ocasionado numerosas críticas que apuntan que la fijación en 1,2 gr. supone una reducción a niveles sobre los que no parece existir seguridad de que el conductor pueda estar afectado en sus capacidades de conducción; al respecto véase LUZÓN PEÑA, D.M., Posibles Reformas de los Delitos de Circulación, en AA.VV., Derecho Penal y Seguridad Vial, Ed. Aranzadi, Navarra, 2007, p. 34; y GUTIÉRREZ RODRÍGUEZ, M., Excesos de Velocidad e Intoxicaciones Punibles, cit., p. 76.

63 DOMÍNGUEZ IZQUIERDO, E.M., La Conducción Bajo la Influencia de Drogas Tóxicas o Bebidas Alcohólicas y la Negativa a Someterse a las Pruebas Dirigidas a la Comprobación de Tales Hechos en Morillas Cueva, L. (Coord.), Delincuencia en Materia de Tráfico y Seguridad Vial, Ed. Dykinson, Madrid, 2007, p. 273.

64 La doctrina jurisprudencial mayoritaria interpreta que para la aplicación del principio «non bis in ídem» el Tribunal Supremo viene exigiendo una triple identidad en el sujeto, hecho y fundamento o bien jurídico. Véase, la STC 1/2009, de 12 de enero (RTC 2009, 1 ), la SAP de Madrid de 13-11-2008 (JUR 2009, 74930) (Sección 3 a, la SAP Madrid de 12 de noviembre de 2008 (JUR 2009, 75450) (Sección 16 a , entre otras muchas.

65 VARGAS CABRERA, B., El Delito de Conducción Bajo la Influencia de Bebidas Alcohólicas y Drogas Tóxicas del Artículo 379 C.P., en De Vicente Martínez, R. (Dir), 
inciso segundo del artículo 379.2.2 se valore la conducción del autor para considerar si existe o no relevancia penal en la infracción ${ }^{66}$. Pero como digo, a mi entender las tasas de alcohol inferiores a la objetivada también deberían ser determinadas de manera objetiva para marcar el punto de inflexión que active la intervención penal, ya que hacer depender esta intervención de los rasgos externos de la conducción, que a su vez también dependen de factores como los metereológicos o de señalización del tráfico, despierta una evidente inseguridad jurídica tanto para la sociedad -como merecedora última de protección de una correcta seguridad vial- como para los mismos enjuiciados.

Para terminar, debemos aludir a la penalidad de este delito, ya que el legislador a través de la Ley Orgánica núm. 5/2010 de 22 de junio modificó el régimen de alternatividad de los tipos de los arts. 379 y 384 . Con anterioridad a la entrada en vigor de esta reforma se ofrecía la única opción entre pena de prisión de 3 a 6 meses o multa de 6 a 12 meses (de 12 a 24 meses para el artículo 384) y trabajos en beneficio de la comunidad ${ }^{67}$ de 31 a 180 días, impuestas

Derecho Penal y Seguridad Vial, Ed. Consejo General del Poder Judicial, Madrid, 2007, p. 137.

66 Así lo reiteran Sentencias como la STS núm. 867/2006 de 15 septiembre (RJ 2006\7350) que determina que "Es un criterio jurisprudencial y forense consolidado, que la diferencia entre el ilícito administrativo y el penal, cuando se trata de conducción bajo ingesta alcohólica, radicaba entre otros aspectos, en el carácter meramente formal de la norma administrativa de superar una determinada ingesta alcohólica mediante las oportunas periciales, en tanto que el ilícito penal supera esa trasgresión formal para exigir la acreditación de un peligro real para la seguridad del tráfico, esto es, la influencia en las facultades psicofísicas necesarias para la conducción poniendo en peligro los bienes jurídicos protegidos en la norma.»-Fundamento de Derecho Primero.

67 Acerca de los límites de estos trabajos, véase artículo 49 C.P.: «Los trabajos en beneficio de la comunidad, que no podrán imponerse sin el consentimiento del penado, le obligan a prestar su cooperación no retribuida en determinadas actividades de utilidad pública, que podrán consistir, en relación con delitos de similar naturaleza al cometido por el penado, en labores de reparación de los daños causados o de apoyo o asistencia a las víctimas, así como en la participación del penado en talleres o programas formativos o de reeducación, laborales, culturales, de educación vial, sexual y otros similares. Su duración diaria no podrá exceder de ocho horas y sus condiciones serán las siguientes:

1. ${ }^{a}$ La ejecución se desarrollará bajo el control del Juez de Vigilancia Penitenciaria, que, a tal efecto, requerirá los informes sobre el desempeño del trabajo a la Administración, entidad pública o asociación de interés general en que se presten los servicios.

2. ${ }^{a} \quad$ No atentará a la dignidad del penado.

3. ${ }^{a}$ El trabajo en beneficio de la comunidad será facilitado por la Administración, la cual podrá establecer los convenios oportunos a tal fin.

4. ${ }^{a}$ Gozará de la protección dispensada a los penados por la legislación penitenciaria en materia de Seguridad Social.

5. ${ }^{a} \quad$ No se supeditará al logro de intereses económicos. 
estas dos penas últimas conjuntamente. De manera que tras la L.O núm. 5/2010 se establecen tres opciones y cabe imponer la pena de prisión, la de multa o la de trabajos en beneficio de la comunidad por separado ${ }^{68}$ (y, en cualquier caso, con la de privación del derecho a conducir vehículos a motor y ciclomotores por tiempo superior a uno y hasta cuatro años), si bien en caso de no aceptación por parte del condenado de la pena elegida, su negativa implicará la prisión. Al respecto habremos de apuntar que según el Preámbulo de esta Ley Orgánica se justificaba la reforma en la búsqueda de una mayor proporcionalidad en la respuesta jurídico penal a determinadas conductas de peligro abstracto eliminándose la anterior disyuntiva entre la pena de prisión y la de multa, y trabajos en beneficio de la comunidad al establecerse los tres tipos de penas como alternativas. De este modo se concede mayor grado de discrecionalidad al Juez para decidir acerca de la imposición de cualquiera de las tres penas

$6^{a} \quad$ Los servicios sociales penitenciarios, hechas las verificaciones necesarias, comunicarán al Juez de Vigilancia Penitenciaria las incidencias relevantes de la ejecución de la pena y, en todo caso, si el penado:

a) Se ausenta del trabajo durante al menos dos jornadas laborales, siempre que ello suponga un rechazo voluntario por su parte al cumplimiento de la pena.

b) A pesar de los requerimientos del responsable del centro de trabajo, su rendimiento fuera sensiblemente inferior al mínimo exigible.

c) Se opusiera o incumpliera de forma reiterada y manifiesta las instrucciones que se le dieren por el responsable de la ocupación referida al desarrollo de la misma.

d) Por cualquier otra razón, su conducta fuere tal que el responsable del trabajo se negase a seguir manteniéndolo en el centro.

Una vez valorado el informe, el Juez de Vigilancia Penitenciaria podrá acordar su ejecución en el mismo centro, enviar al penado para que finalice la ejecución de la misma en otro centro o entender que el penado ha incumplido la pena.

En caso de incumplimiento, se deducirá testimonio para proceder de conformidad con el artículo 468.

7. ${ }^{a}$ Si el penado faltara del trabajo por causa justificada no se entenderá como abandono de la actividad. No obstante, el trabajo perdido no se le computará en la liquidación de la condena, en la que se deberán hacer constar los días o jornadas que efectivamente hubiese trabajado del total que se le hubiera impuesto.»

${ }_{68}$ Recordemos que según el Real Decreto 840/2011 de 17 de junio -por el que se establecen las circunstancias de ejecución de las penas de trabajo en beneficio de la comunidad y de localización permanente en centro penitenciario, de determinadas medidas de seguridad, así como de la suspensión de la ejecución de la penas privativas de libertad y sustitución de penas- los Trabajos en Beneficio de la Comunidad se definen como aquellos que, «no podrán imponerse sin el consentimiento del penado, le obligan a prestar su cooperación no retribuida en determinadas actividades de utilidad pública, que podrán consistir, en relación con delitos de similar naturaleza al cometido por el penado, en labores de reparación de los daños causados o de apoyo o asistencia a las víctimas, así como en la participación del penado en talleres o programas formativos o de reeducación, laborales, culturales, de educación vial, sexual y otros similares»- Artículo2.1. Véase este Real Decreto para profundizar en la forma de organización de estos trabajos. 
previstas, siendo lo previsible que se reserve la pena de prisión para los supuestos más graves, contándose además con la posibilidad de rebajar el grado atendiendo a la menor entidad del riesgo y a las demás circunstancias del hecho enjuiciado.

De manera que en parte me preocupa también la ausencia de un criterio más objetivo para la determinación de la condena, ya que entonces podemos considerar que esta reforma deposita en manos del juzgador el arbitrio de qué pena será la más idónea para el condenado, barajándose penas de carácter tán distinto como la de prisión o multa, a mi entender con claro efecto disuasorio, o la de trabajos en beneficio de la comunidad de carácter más rehabilitador ${ }^{69}$ según fin de prevención especial de la pena ${ }^{70}$. Pero en este extremo incidiré más adelante en el apartado de las Conclusiones.

Seguidamente, ya que conocemos el alcance del delito penal del artículo $379.2 \mathrm{CP}$ y que hemos comentado las cuestiones más importantes que del mismo derivan, vamos a detenernos en dos problemas de relevancia que se nos pueden plantear en su enjuiciamiento y que vamos a analizar en el siguiente Apartado.

69 Al respecto, véase el artículo 5 del citado Real Decreto 840/2011 por el que, "1. Los servicios de gestión de penas y medidas alternativas, una vez recibidos el mandamiento u orden judicial de ejecución y los particulares necesarios, realizarán la valoración del caso para determinar la actividad más adecuada, informando al penado de las distintas plazas existentes, con indicación expresa de su cometido y del horario en que debería realizarlo; así mismo, se escuchará la propuesta que el penado realice.

Cuando las circunstancias o características vinculadas a la persona condenada, o derivadas de su etiología delictiva, así lo aconsejen, los profesionales de los servicios de gestión de penas y medidas alternativas ofertarán al penado que la pena de trabajo en beneficio de la comunidad se cumpla con su participación en talleres o programas formativos o de reeducación, laborales, culturales, de educación vial, sexual y otros similares, de los que la Administración Penitenciaria venga desarrollando como parte de las políticas públicas de esta naturaleza, o que cuenten con su aprobación si el cumplimiento mediante esta modalidad se realizara en un ámbito o institución no penitenciaria.

2. Al citar al penado, los servicios de gestión de penas y medidas alternativas le advertirán de las consecuencias de su no comparecencia. En los supuestos de incomparecencia no justificada remitirán los testimonios oportunos al órgano jurisdiccional competente para la ejecución.

3. Realizada la valoración, se elaborará el plan de ejecución dándose traslado al Juzgado de Vigilancia Penitenciaria para su control, sin perjuicio de su inmediata ejecutividad.

No obstante, en el caso de que el penado acredite fehacientemente que se opone al cumplimiento del plan de ejecución, se informará al Juez de Vigilancia Penitenciaria de tal hecho, a los efectos que considere oportunos."

70 VARGAS CABRERA, B., El Delito de Conducción Bajo la Influencia de Bebidas Alcohólicas y Drogas Tóxicas del artículo 379 C.P., cit., p. 189. 


\section{CUESTIONES RELEVANTES DE SU ENJUICIAMIENTO}

Estas cuestiones son:

a) La posible vulneración del derecho a la intimidad del autor sometido a la prueba de alcoholemia.

b) Las consecuencias de la negativa del autor a realizar esta prueba.

Empecemos por la primera de ellas.

\section{III.1. Posible Vulneración del Derecho a la Intimidad del Autor sometido a la Prueba de Alcoholemia}

Al tratarse entonces de un delito en el que la acción típica se conforma por la mera conducción bajo la tasa de alcohol mencionada adquiere singular importancia la manera de detectar esa tasa y con ello, la prueba de alcoholemia en sí. Para su concreción no deja de resultar un problema que nos encontremos ante una norma penal en blanco, dada la remisión normativa a un referente extrapenal de referencia para describir la acción típica que realiza el artículo 796.7 de la LECr., donde se especifica que «la práctica de los controles de alcoholemia se ajustará a lo establecido en la legislación de seguridad vial», con lo que será necesaria la remisión a los artículos 23 a 26 del Reglamento General de Circulación aprobado por Real Decreto núm. 1428/2003 de 21 de noviembre ${ }^{71}$ para conocer la forma en la que habrá de realizarse tán relevante test.

71 Artículo 22. Pruebas de detección alcohólica mediante el aire espirado.

«1. Las pruebas para detectar la posible intoxicación por alcohol se practicarán por los agentes encargados de la vigilancia de tráfico y consistirán, normalmente, en la verificación del aire espirado mediante etilómetros que, oficialmente autorizados, determinarán de forma cuantitativa el grado de impregnación alcohólica de los interesados.

A petición del interesado o por orden de la autoridad judicial, se podrán repetir las pruebas a efectos de contraste, que podrán consistir en análisis de sangre, orina u otros análogos (artículo 12.2, párrafo segundo, in fine, del texto articulado).

2. Cuando las personas obligadas sufrieran lesiones, dolencias o enfermedades cuya gravedad impida la práctica de las pruebas, el personal facultativo del centro médico al que fuesen evacuados decidirá las que se hayan de realizar.»

Artículo 23. Práctica de las pruebas.

«1. Si el resultado de la prueba practicada diera un grado de impregnación alcohólica superior a 0,5 gramos de alcohol por litro de sangre o a 0,25 miligramos de alcohol por litro de aire espirado, o al previsto para determinados conductores en el artículo $20 \mathrm{o}$, aun sin alcanzar estos límites, presentara la persona examinada síntomas evidentes de encontrarse bajo la influencia de bebidas alcohólicas, el agente 


\section{También considero importante que nos refiramos a la Orden} ITC/3707/2006 de 22 de noviembre por la que se regula el Control

someterá al interesado, para una mayor garantía y a efecto de contraste, a la práctica de una segunda prueba de detección alcohólica por el aire espirado, mediante un procedimiento similar al que sirvió para efectuar la primera prueba, de lo que habrá de informarle previamente.

2. De la misma forma advertirá a la persona sometida a examen del derecho que tiene a controlar, por sí o por cualquiera de sus acompañantes o testigos presentes, que entre la realización de la primera y de la segunda prueba medie un tiempo mínimo de 10 minutos.

3. Igualmente, le informará del derecho que tiene a formular cuantas alegaciones $u$ observaciones tenga por conveniente, por sí o por medio de su acompañante o defensor, si lo tuviese, las cuales se consignarán por diligencia, y a contrastar los resultados obtenidos mediante análisis de sangre, orina u otros análogos, que el personal facultativo del centro médico al que sea trasladado estime más adecuados.

4. En el caso de que el interesado decida la realización de dichos análisis, el agente de la autoridad adoptará las medidas más adecuadas para su traslado al centro sanitario más próximo al lugar de los hechos. Si el personal facultativo del centro apreciara que las pruebas solicitadas por el interesado son las adecuadas, adoptará las medidas tendentes a cumplir lo dispuesto en el artículo 26.

El importe de dichos análisis deberá ser previamente depositado por el interesado y con él se atenderá al pago cuando el resultado de la prueba de contraste sea positivo; será a cargo de los órganos periféricos del organismo autónomo Jefatura Central de Tráfico o de las autoridades municipales o autonómicas competentes cuando sea negativo, devolviéndose el depósito en este último caso.»

Artículo 24. Diligencias del agente de la autoridad.

«Si el resultado de la segunda prueba practicada por el agente, o el de los análisis efectuados a instancia del interesado, fuera positivo, o cuando el que condujese un vehículo de motor presentara síntomas evidentes de hacerlo bajo la influencia de bebidas alcohólicas o apareciera presuntamente implicado en una conducta delictiva, el agente de la autoridad, además de ajustarse, en todo caso, a lo establecido en la Ley de Enjuiciamiento Criminal, deberá:

a) Describir con precisión, en el boletín de denuncia o en el atestado de las diligencias que practique, el procedimiento seguido para efectuar la prueba o pruebas de detección alcohólica, haciendo constar los datos necesarios para la identificación del instrumento o instrumentos de detección empleados, cuyas características genéricas también detallará.

b) Consignar las advertencias hechas al interesado, especialmente la del derecho que le asiste a contrastar los resultados obtenidos en las pruebas de detección alcohólica por el aire espirado mediante análisis adecuados, y acreditar en las diligencias las pruebas o análisis practicados en el centro sanitario al que fue trasladado el interesado.

c) Conducir al sometido a examen, o al que se negase a someterse a las pruebas de detección alcohólica, en los supuestos en que los hechos revistan caracteres delictivos, de conformidad con lo dispuesto en la Ley de Enjuiciamiento Criminal, al juzgado correspondiente a los efectos que procedan.»

Artículo 25: Inmovilización del vehículo.

«1. En el supuesto de que el resultado de las pruebas y de los análisis, en su caso, fuera positivo, el agente podrá proceder, además, a la inmediata inmovilización del vehículo, mediante su precinto u otro procedimiento efectivo que impida su circulación, a no ser que pueda hacerse cargo de su conducción otra persona debidamente habilitada, 
Metrológico del Estado de los Instrumentos destinados a medir la Concentración de Alcohol en el Aire Espirado y donde se regulan los controles y demás obligaciones para que la medición de estos aparatos no pueda ser impugnada por las defensas, así como, la Orden JUS/1291/2010 de 13 de mayo por la que se aprueban las Normas para la Preparación y Remisión de Muestras Objeto de Análisis por el Instituto Nacional de Toxicología y Ciencias Forenses; si bien no voy a profundizar en el estudio de estas Ordenes por no ser objeto del tema que analizamos, y ello pese a su íntima relación con él, y voy a continuar partiendo de la base que la medición realizada y que conforma el delito de estudio se ha realizado por un aparato que reune las debidas garantías, así como que la remisión de las correspondientes muestras se ha hecho con el sigilo correspondiente en la cadena de custodia ${ }^{72}$.

y proveerá cuanto fuese necesario en orden a la seguridad de la circulación, la de las personas transportadas en general, especialmente si se trata de niños, ancianos, enfermos o inválidos, la del propio vehículo y la de su carga.

2. También podrá inmovilizarse el vehículo en los casos de negativa a efectuar las pruebas de detección alcohólica (artículo 70, in fine, del texto articulado).

3. Salvo en los casos en que la autoridad judicial hubiera ordenado su depósito o intervención, en los cuales se estará a lo dispuesto por dicha autoridad, la inmovilización del vehículo se dejará sin efecto tan pronto como desaparezca la causa que la motivó o pueda sustituir al conductor otro habilitado para ello que ofrezca garantía suficiente a los agentes de la autoridad y cuya actuación haya sido requerida por el interesado.

4. Los gastos que pudieran ocasionarse por la inmovilización, traslado y depósito del vehículo serán de cuenta del conductor o de quien legalmente deba responder por él.»

Artículo 26. Obligaciones del personal sanitario.

«1. El personal sanitario vendrá obligado, en todo caso, a proceder a la obtención de muestras y remitirlas al laboratorio correspondiente, y a dar cuenta, del resultado de las pruebas que se realicen, a la autoridad judicial, a los órganos periféricos del organismo autónomo Jefatura Central de Tráfico y, cuando proceda, a las autoridades municipales competentes (artículo 12.2, párrafo tercero, del texto articulado).

Entre los datos que comunique el personal sanitario a las mencionadas autoridades u órganos figurarán, en su caso, el sistema empleado en la investigación de la alcoholemia, la hora exacta en que se tomó la muestra, el método utilizado para su conservación y el porcentaje de alcohol en sangre que presente el individuo examinado.

2. Las infracciones a las distintas normas de este capitulo, relativas a la conducción habiendo ingerido bebidas alcohólicas o a la obligación de someterse a las pruebas de detección alcohólica, tendrán la consideración de infracciones muy graves, conforme se prevé en el artículo 65.5.a) y b) del texto articulado.»

72 Para profundizar en estas garantías en la realización de la prueba véase, CLIMENT DURÁN, C., La Prueba en los Delitos contra la Seguridad del Tráfico, en De Vicente Martínez, R. (Dir), Derecho Penal y Seguridad Vial, Ed. Consejo General del Poder Judicial, Madrid, 2007, pp. 359 a 404. 
Dentro de estas garantías alcanza esencial significado el derecho constitucional a la intimidad ${ }^{73}$ porque a través de la práctica de esta prueba se puede obtener una información que el sujeto quizás no quiera desvelar lo que puede suponer una intromisión añadida en el ámbito constitucionalmente protegido ${ }^{74}$. Para su comentario y por su ejemplaridad me referiré a la Sentencia del Tribunal Constitucional núm. 25/2005 de 14 de febrero -RTC 2005\25-que determina de manera muy concreta los requisitos que se han de dar para no entender conculcado este derecho a la intimidad corporal al recogerse en su texto que en definitiva, el derecho a la intimidad no es absoluto pues cede ante intereses constitucionalmente relevantes siempre que el recorte que haya de experimentar se revele como necesario para lograr el fin legítimo previsto, sea proporcionado para alcanzarlo y en todo caso, sea respetuoso con el contenido esencial del derecho ${ }^{75}$. Por lo tanto, la afectación ha de presentar una justificación objetiva y razonable debiendo recordarse que los requisitos que conforman nuestra doctrina sobre la proporcionalidad y que resultan rigurosamente aplicables son: que la medida limitativa del derecho fundamental esté prevista por la Ley, que sea adoptada mediante resolución judicial especialmente motivada, y que sea idónea, necesaria y proporcionada en relación con un fin constitucionalmente legítimo; argumento utilizado de forma unánime por la jurisprudencia cons-

73 Artículo 18 de la Constitución Española:

«1. Se garantiza el derecho al honor, a la intimidad personal y familiar y a la propia imagen.

2. El domicilio es inviolable. Ninguna entrada o registro podrá hacerse en él sin consentimiento del titular o resolución judicial, salvo en caso de flagrante delito.

3. Se garantiza el secreto de las comunicaciones y, en especial, de las postales, telegráficas y telefónicas, salvo resolución judicial.

4. La ley limitará el uso de la informática para garantizar el honor y la intimidad personal y familiar de los ciudadanos y el pleno ejercicio de sus derechos.»

74 Según doctrina reiterada del Tribunal Constitucional, «el derecho a la intimidad personal, en cuanto derivación de la dignidad de la persona (artículo 10.1 CE), implica «la existencia de un ámbito propio y reservado frente a la acción y el conocimiento de los demás, necesario, según las pautas de nuestra cultura, para mantener una calidad mínima de la vida humana»»-SSTC núm. 231/1988, de 2 de diciembre [RTC 1988/ 231], núm. 197/1991, de 17 de octubre [RTC 1991/ 197], núm. 20/1992, de 14 de febrero [RTC 1992/20], núm. 219/1992, de 3 de diciembre [RTC 1992/ 219], núm. 142/1993 de 22 de abril [RTC 1993/ 142], 117/1994, de 25 de abril [RTC 1994/ 117], y núm. 143/1994, de 9 de mayo [RTC 1994/ 143]-, y «referido preferentemente a la esfera, estrictamente personal, de la vida privada o de lo íntimo» -SSTC núm. 142/1993, de 22 de abril (RTC 1993/142), y núm. 143/1994, de 9 de mayo (RTC 1994/143).

75 STC núm. 57/1994 de 28 de febrero (RTC 1994/ 57), Fundamento Jurídico Sexto, citada a modo de ejemplo. 
titucional ${ }^{76}$. A su vez, tanto desde la doctrina como en la jurisprudencia constitucional se insiste de forma unánime, claro está, en la necesidad de dotar a esta pruebas de determinadas garantías en su realización, descartando como no, el ejercicio de la fuerza en su realización ${ }^{77}$.

Pues bien, este criterio de proporcionalidad de los sacrificios viene contemplado en numerosas resoluciones y se refiere a que es de observancia obligada al afectar a la limitación de un derecho fundamental y comprende que el respeto de esta regla impone la motivación de la resolución judicial que excepcione o restrinja el derecho, pues sólo tal fundamentación permitirá que se aprecie la razón que justificó a juicio del órgano judicial el sacrificio del derecho fundamental ${ }^{78}$. En su virtud, el órgano jurisdiccional debe plasmar el juicio de ponderación entre el derecho fundamental afectado y el interés constitucionalmente protegido y perseguido del cual se evidencie la necesidad de la adopción de la medida, siendo doctrina reiterada del Tribunal Constitucional que su ausencia ocasiona por sí sola en estos casos la vulneración del derecho fundamental sustantivo ${ }^{79}$.

Por lo anterior, y pese a que la relación del derecho a la intimidad con la realización de pruebas como la de alcoholemia ha sido un tema muy polémico, la constitucionalidad de su realización está asentada en nuestra jurisprudencia al adquirir esencial relevancia en su valoración la envergadura del bien jurídico tutelado y la necesidad de la realización de esta prueba para su preservación. A mi criterio y por todo lo ya expuesto en el Apartado anterior, secundo esta valoración acerca de la proporcionalidad de esta prueba y según el fin último al que va destinada la norma. La intimidad del autor ha de ceder ante la posibilidad de una comisión delictiva de esta índole, ya que las repercusiones de la tasa de alcohol sobre la seguridad del tráfico son de tal índole y conllevan unas consecuencias de tanto al-

76 Fragmento de la STC 207/1996 de 16 de diciembre (RTC 1996/ 207), Fundamento Jurídico Cuarto que cito por su concreción en la enumeración de estos requisitos para no entenderse conculcado el derecho a la intimidad.

77 Garantías tratadas en muchas resoluciones, por su fundamentación véase la STS núm. 207/1996 de 16 de diciembre (RTC 1996/83136)- Fundamento de Derecho Cuarto.

Véase también GONZÁLEZ CUÉLLAR-SERRANO, N., Proporcionalidad y Derechos Fundamentales en el Proceso Penal, Ed. Colex, Madrid, 1990, p. 285; e IGLESIAS CANLÉ, I.C., La Nueva Regulación de las Medidas de Intervención Corporal en el Artículo 363.2 de la L.E.Crim., en González Cuellar-Serrano, N. (Dir.), Investigación y Prueba en el Proceso Penal, Ed. Colex, Madrid, 2006, p. 175.

78 STC 37/1989, de 15 de febrero (RTC 1989/ 37), Fundamento Jurídico Octavo.

79 Citado por muchas, a modo de muestra, la STC 207/1996, de 16 de diciembre (RTC 1996/ 207), Fundamento Jurídico Cuarto. 
cance que considero idónea la proporcionalidad de la prueba en los términos que ha manifestado reiterado el Tribunal Constitucional.

También se planteó la vulneración con estas pruebas del derecho a la integridad física del artículo constitucional número $15^{80}$, pero éste fue rápidamente descartado ${ }^{81}$ incluso desde antaño si consultamos la Decisión de la Comisión Europea de Derechos Humanos núm. 8278/1978 de 13 de diciembre de 1979, valoración que han secundado con unanimidad la jurisprudencia ${ }^{82}$.

Ahora bien, otra cuestión va a ser que pese a que se entienda que con la realización del test de alcohol no se está vulnerando ningún derecho constitucional, el sujeto implicado se niegue a la realización de la misma, circunstancia que vamos a analizar en las siguientes líneas y donde como veremos, para valorar esta cuestión muchos autores ponen de nuevo en entredicho la constitucionalidad de la prueba.

\section{III.2. Consecuencias de la Negativa a Realizar la Prueba}

Dispone el artículo $383 \mathrm{CP}$ en su redacción actual -introducida por la Ley Orgánica 15/2007, de 30 de noviembre - que, «el conductor, que requerido por un agente de la autoridad, se negare a someterse a las pruebas legalmente establecidas para la comprobación de las tasas de alcoholemia y la presencia de drogas tóxicas, estupefacientes y sustancias psicotrópicas a que se refieren los artículos anteriores, será castigado con la penas de prisión de seis meses a un año y privación del derecho a conducir vehículos a motor y ciclomotores por tiempo superior a uno y hasta cuatro años".

Ahora bien, resulta importante poner aquí de manifiesto que el artículo 383 es un delito doloso que exige conciencia y voluntad del conductor respecto de su oposición al cumplimiento del requeri-

80 «Todos tienen derecho a la vida y a la integridad física y moral, sin que, en ningún caso, puedan ser sometidos a tortura ni a penas o tratos inhumanos o degradantes.»

81 La vulneración del derecho a la integridad física ha suscitado menos controversia por entenderse irrelevante la prueba del alcohol para la esfera corporal. Este criterio es avalado por muchos, por su ilustración véase MAGALDI PATERNOSTRO, M.J., El Tipo del Artículo380 del Código Penal: Una Propuesta Interpretativa, en De Vicente Martínez, R. (Dir), Derecho Penal y Seguridad Vial, Ed. Consejo General del Poder Judicial, Madrid, 2007, p. 219.

82 Véase como ejemplo, la STC núm. 103/1985 de 4 de octubre (RTC 1985/103) por la que ni siquiera la prueba de extracción de sangre es considerada vulneradora de este derecho- Fundamento de Derecho Tercero. 
miento efectuado, dolo que abarca el conocimiento de la obligación de realizar las pruebas y la negativa de llevarlas a cabo a pesar de ese conocimiento.

Tras esta aclaración, habremos de mencionar que la cuestión de la negativa a realizar estas pruebas ha sido muy debatida por la doctrina, de manera que hay autores que afirman que tal negativa podría estar orientada a la defensa de los intereses propios en el eventual proceso, lo cual la sitúa al menos prima facie, en el ámbito del derecho a la defensa del artículo 24.2 de la CE, y por lo tanto dicha conducta no implicaría la intención específica de menoscabar el principio de autoridad $^{83}$. Con esta tesis afirman que la penalización de la desobediencia de someterse a la prueba de alcoholemia denota una instrumentalización del ciudadano y todo un exceso de intervención penal ${ }^{84}$ al ser ésta una solución excesivamente radical ${ }^{85}$, ya que según argumentan, los bienes jurídicos no pueden protegerse a cualquier precio y menos aún, cuando están implicados derechos fundamentales ${ }^{86}$.

Para argumentar este criterio se alude a que la finalidad de esta penalización es ejemplarizante para la concienciación colectiva pero también es una muestra palpable del abuso por parte del legislador de las exigencias de prevención general negativa ${ }^{87}$, y representa una desproporción por el hecho de imponer una pena para facilitar la indagación de si se ha realizado una conducta delictiva al limitarse con ésto el derecho a la libertad, a la intimidad y a los derechos procesales ${ }^{88}$.

En cambio, una corriente contraria a la que me uno apunta que no existe esta instrumentalización del hombre como vehículo de mantenimiento de la paz social, ni se atenta contra la dignidad humana ${ }^{89}$, sino que la sanción por no querer someterse a las pruebas de alcoholemia es acorde a las posiciones preventivo generales con los fines y el garantismo penal ${ }^{90}$.

A este respecto, yo no estoy de acuerdo con que si se articulara un control administrativo eficaz la despenalización de la conducta

83 DÍAZ REVORIO, J., La Prueba de Alcoholemia, cit., p. 161.

84 IGLESIAS RÍO, M.A., El Delito de Negativa a Someterse a la Prueba de Alcoholemia, Boletín del Ministerio de Justicia, n. ${ }^{\circ}$ 1845, 1999, p. 1275.

85 Idem., 1286.

86 GIL HERNÁNDEZ, A., Intervenciones Corporales y Derechos Fundamentales, Ed. Constitución y Leyes, Madrid, 1995, p. 122.

87 Con esta argumentación CARMONA SALGADO, M.J., Delitos..., cit., p. 792.

88 IGLESIAS RÍO, M.A., El Delito de Negativa a Someterse a la Prueba de Alcoholemia, cit., p. 1299.

89 OCTAVIO DE TOLEDO Y UBIETO, Sobre el Concepto de Derecho Penal, Ed. Universidad de Madrid, Madrid, 1981, p. 204.

90 Idem. 
del artículo 383 no tendría por qué comportar efectos de bagatelización de las infracciones en el ámbito general del tráfico rodado, ni a minusvalorar los importantes perjuicios causados por siniestros automivilísticos $^{91}$, por ser la multa administrativa de considerable cuantía inequívocamente muy disuasoria ${ }^{92}$, ya que considero la intervención panal necesaria para tratar esta infracción. Para su argumentación debemos resaltar que la conducción bajo la influencia de las drogas o el alcohol no sólo constituye un comportamiento delictivo autónomo, sino también una forma de comportamiento imprudente que puede lesionar la vida y la integridad física de las personas, y que la obligación de someterse a las pruebas referidas en el artículo 383 no pretende únicamente la detección y evitación de una conducta peligrosa, sino que se dirige instrumentalmente también a la detección y evitación de la comisión de homicidios y lesiones imprudentes ${ }^{93}$.

Los requisitos que conforman nuestra doctrina sobre la proporcionalidad en la exigencia de realización de la prueba y que resultan rigurosamente aplicables son: que la medida limitativa del derecho fundamental esté prevista por la Ley, que sea adoptada mediante resolución judicial especialmente motivada, y que sea idónea, necesaria y proporcionada en relación con un fin constitucionalmente legítimo $^{94}$. Y es que, el Tribunal Constitucional ha mantenido un criterio invariable en el que propugna que «la verificación de la prueba que se considera supone, para el afectado, un sometimiento, no ilegítimo desde la perspectiva constitucional, a las normas de policía, sometimiento al que, incluso, puede verse obligado sin la previa existencia de indicios de infracción, en el curso de controles preventivos realizados por los encargados de velar por la regularidad y seguridad del tránsito»-Fundamento Jurídico Cuarto SSTC núm. 252/1994 (RTC 1994\252 ).

En este sentido también es unánime el Tribunal Constitucional cuando determina que el deber de someterse al control de alcoholemia no puede considerarse contrario al derecho a no declarar contra sí mismo y a no confesarse culpable, pues no se obliga al detectado a emitir una declaración que exteriorice un contenido, admitiendo su culpabilidad, sino a tolerar que se le haga objeto de una especial

91 IGLESIAS RÍO, M.A., El Delito de Negativa a Someterse a la Prueba de Alcoholemia, cit., p. 1268.

92 Idem., p. 1272 y 1274.

93 Utilizando palabras del Fundamento Jurídico Trece de la Sentencia del Tribunal Constitucional Núm. 161/1997 de 2 octubre (RTC 1997\161).

94 Doctrina consolidada en el Tribunal Constitucional, por su importancia véase la STC 207/1996, de 16 de diciembre (RTC 1996/ 207), Fundamento de Derecho Cuarto. 
modalidad de pericia, exigiéndole una colaboración no equiparable a la declaración comprendida en el ámbito de los derechos proclamados en los arts. 17.3 y 24.2 de la Constitución ${ }^{95}$. Y pese a que el sometimiento a la prueba puede aportar un resultado autoincriminatorio ${ }^{96}$, avalo la consideración de que no debería de equipararse su realización a la declaración del autor reconociendo su culpabilidad.

En lo referente al bien tutelado en este artículo 383 el debate doctrinal es similar al que hemos reproducido para el artículo 379.2, decantándose parte de la doctrina por entender que estamos ante un delito de desobediencia ${ }^{97}$ y ser el objeto de tutela el principio de autoridad, entendido éste como la dignidad que debe acompañar el ejercicio legítimo de la función pública ${ }^{98}$, o incluso algunos autores ${ }^{99}$ establecen que el bien tutelado es la eficacia preventiva del artículo 379.2. Mientras, en otro extremo, están los autores a los que secundo que entienden que el objeto de tutela es la seguridad del tráfico ${ }^{100}, \mathrm{y}$ ello pese a los problemas concursales que comporta la determinación de un mismo bien jurídico para los delitos de los artículos 383 y 379.2, ya que la determinación de un mismo objeto de tutela en ambos nos conducirá a la resolución del conflicto concursal como un concurso de normas ${ }^{101}$-del artículo penal $8^{102}$ - y no a un concurso

95 STC 103/1985 de 4 octubre (RTC 1985\103), Fundamento de Derecho Segundo.

También la STC núm. 161/1997 de 2 octubre (RTC 1997 161) resulta aclaratoria al afirmar con contundencia que, "las pruebas para la comprobación de la conducción bajo la influencia del alcohol o de drogas tóxicas, estupefacientes o sustancias psicotrópicas, y, entre ellas, las de espiración de aire a través de un alcoholímetro, no constituyen en rigor una declaración o testimonio, por lo que no pueden suponer vulneración alguna de los derechos a no declarar, a no declarar contra uno mismo y a no confesarse culpable.»-Fundamento de Derecho Segundo.

96 DÍAZ REVORIO, F.J., La Prueba de Alcoholemia y sus Consecuencias en los ámbitos Administrativo-Sancionador y Penal, en Parlamento y Constitución, Anuario Núm.4, 2000, p. 133.

97 CARMONA SALGADO, C., Delitos..., cit., p. 786; y De Vicente Martínez, R., Derecho Penal de la Circulación, Ed. Bosch, Barcelona, 2006, p. 330.

98 ORTS BERENGUER ORTS BERENGUER, E., Delitos contra la Seguridad del Tráfico, cit., p. 1717.

${ }_{99}$ Véase como ejemplo, ALONSO RIMO, A., La Negativa a Someterse a las Pruebas de Detección de Alcohol, Drogas Tóxicas o Sustancias Similares como Modalidad de Desobedencia Penal, en Revista Derecho y Proceso Penal, núm. 2, 2003, p. 66.

100 MAGALDi PATERNOSTRO, M.J., El Tipo del Artículo 380 del Código Penal: Una Propuesta Interpretativa, cit., p. 215.

101 Como muestra de la corriente doctrinal que defiende esta resolución del concurso, véase a MARTÍNEZ RUIZ, J., El Delito de Desobedencia a los Agentes de la Autoridad en el ámbito de la Seguridad Vial, en Morillas Cueva, L. (Coord.), Delincuencia en Materia de Tráfico y Seguridad Vial: aspectos penales, civiles y procesales, Ed. Dykinson, Madrid, 2007, p. 246.

102 "Los hechos susceptibles de ser calificados con arreglo a dos o más preceptos de este Código, y no comprendidos en los artículos 73 a 77, se castigarán observando

(C) UNED. Revista de Derecho UNED, núm. 13, 2013 
real de infracciones, ya que la aplicación de uno de los delitos allí contenidos sería suficiente para abarcar el desvalor total de la conducta contra la protegida seguridad vial ${ }^{103}$.

Para mí la ubicación sistemática de este delito entre aquellos "contra la Seguridad del Tráfico» y el fin teleológico de la norma que es la comprobación de los hechos descritos en el artículo 379.2 y la detección de sustancias típicas en los conductores que pudieran poner en riesgo la seguridad vial son argumentos suficientes para que sea considerada esta seguridad el bien tutelado, ya que el artículo 383 penaliza una desobediencia sí, pero íntimamente vinculada a la seguridad vial ${ }^{104}$.

Y es que, en efecto, la conducción de vehículos a motor es una actividad que puede poner en muy grave peligro la vida y la integridad física de las personas y ello provoca que sea justificable que exista un intervencionismo tal que asegure que el ejercicio de esa actividad se desarrolle con el cumplimiento de severos requisitos y que su incumplimiento sea sancionado según la relevancia del bien que se pretende proteger. De forma que la obligación de someterse a las pruebas de detección de alcohol tiene como objetivo comprobar si los conductores cumplen las normas establecidas para garantizar ese bien a tutelar, y entiendo que su sometimiento no supone una autoincriminación en relación con un delito contra la seguridad en el tráfico, sino que constituye un delito específico que encuentro tiene su razón de ser. No comparto la necesidad de que se dé una conducción temeraria $^{105}$ para que se justifique la realización de las pruebas que comen-

las siguientes reglas:

1. ${ }^{a}$ El precepto especial se aplicará con preferencia al general.

2. ${ }^{a} \quad$ El precepto subsidiario se aplicará sólo en defecto del principal, ya se declare expresamente dicha subsidiariedad, ya sea ésta tácitamente deducible.

3. $^{a}$ El precepto penal más amplio o complejo absorberá a los que castiguen las infracciones consumidas en aquél.

4. ${ }^{a}$ En defecto de los criterios anteriores, el precepto penal más grave excluirá los que castiguen el hecho con pena menor.»

103 En cambio, la determinación de bienes tutelados distintos nos conduciría al establecimiento de un concurso real de delitos que habrá de resolverse según artículo 73 C.P. Con este criterio véase por su argumentación, Sánchez Moreno, J., Negativa a Someterse a las Pruebas de Alcoholemia, Ed. Bosch, Barcelona, 2008, p. 13.

104 DOMÍNGUEZ IZQUIERDO, E.M., La Conducción Bajo la Influencia de Drogas Tóxicas o de Bebidas Alcohólicas y la Negativa a Someterse a las Pruebas Dirigidas a la Comprobación de Tales Hechos, en Morillas Cueva, L. (Coord.), Delincuencia en Materia de Tráfico y Seguridad Vial, Ed. Dykinson, Madrid, 2007, p. 285; Molina Fernández, R., en Bajo Fernández, M., (Dir.), Compendio de Derecho Penal. Parte Especial, Ed. Ceura, Madrid, 1998, p. 727.

105 Exigida por autores como MAGALDI PATERNOSTRO, M.J., El Tipo del Artículo 380 del Código Penal: Una Propuesta Interpretativa, cit., p. 225. 
tamos con el fin de esclarecer a qué se debe esa conducción irregular, para mí, y por los mismos argumentos que expuse en el Apartado anterior, el que en un control rutinario se inste a la realización de estas pruebas y el autor se niegue a su realización ya es motivo suficiente para justificar una intervención penal por la relevancia que esta negativa va a tener, y que en ningún caso estaría suficientemente sancionada por vía administrativa, en los mismos términos a los que me adhiero que son defendidos por un amplio sector doctrinal ${ }^{106}$.

Ahora bien, sí que hay que insistir en la necesidad de la concurrencia en esta negativa de dos elementos, esto es, el intelectual y el volitivo, y que recuerdan la exigencia de que el conductor manifieste expresamente su entendimiento de que ha sido requerido para la realización de dichas pruebas y que es su voluntad no acceder a la misma. Así, la jurisprudencia insiste en este extremo y recalca la importancia de justificar ambos elementos ${ }^{107}$. En este sentido resultan muy notables resoluciones como la Sentencia de la Audiencia Provincial de Cádiz núm. 138/2009 de 13 abril (JUR 2010/188936) en la que se absuelve a la acusada por considerar la Sala que no constaba acreditado que ésta fuera informada suficientemente de las consecuencias penales de su negativa, resaltándose en este caso que se trataba de una ciudadana alemana que no hablaba español y tenía muchas dificultades de comprensión, surgiendo por tanto la duda razonable en relación con la intencionalidad de la acusada en el momento de negarse a someterse a la prueba alcoholométrica, esto es, el elemento intelectual y su conocimiento acerca de estar con ello incurriendo en una conducta antijurídica ${ }^{108}$.

106 Por citar un ejemplo de esta corriente con el argumento de la plena idoneidad del delito recogido en el artículo 383 C.P véase, OLMEDO CARDENETE, M., Aspectos Prácticos de los Delitos contra la Seguridad del Tráfico Tipificados en los Arts. 379 y 380 del Código Penal, Ed. Revista Electrónica de Ciencia Penal y Criminología, núm. 4, 2002, p. 12.

107 Por citar una muestra de esta jurisprudencia aludamos a la Sentencia de la Audiencia Provincial de Valencia núm. 260/2011 de 6 de abril (JUR 2011/241349) en la que se absuelve al acusado porque en ningún momento se negó a someterse a las pruebas de detección alcohólica, sino que manifestaba que su traqueotomía le impedía hacerlas con garantías.

También encontramos numerosas resoluciones que absuelven por ausencia de un requerimiento expreso del agente de la autoridad, ya que éste debe ser expreso, terminante y claro, y debe ir acompañado de la información sobre la causa que lo motiva y las consecuencias jurídicas que se derivan de la negativa.

108 La STS núm. 826/2012 de 27 julio (JUR 2012\332775), por citar más ejemplos de la necesidad de que la comprensión y voluntad del conductor se reflejen de manera inequívoca, no reconoce el delito de negativa ya que se entiende que los agentes de la policía no extendieron la correspondiente acta de la negativa a someterse a la prueba de alcoholemia, no constando formalmente el requerimiento de los agentes y 
Y es por la necesidad de concurrencia de ambos elementos, intelectual y volitivo, por lo que para el caso que un conductor por cualquier motivo carezca de capacidad para expresar su voluntad de someterse a la prueba, para que ésta sea legítima habrá de someterse a autorización judicial ${ }^{109}$ ya que es criterio consolidado la necesidad de que la realización de estas pruebas goce de todas las garantías bajo apercibiendo de nulidad si éstas no estuvieran aseguradas ${ }^{110}$.

Mayores dudas presenta si cabe la inclusión en el tipo penal de la negativa cuando el conductor se somete voluntariamente a la primera prueba y se niega a hacerlo a la segunda. Al encontrarnos ante una norma penal en blanco debemos de mencionar que el artículo 12.2 de la Ley de Seguridad Vial establece que, "Todos los conductores de vehículos y bicicletas quedan obligados a someterse a las pruebas que se establezcan para la detección de las posibles intoxicaciones por alcohol. Igualmente quedan obligados los demás usuarios de la vía

la negativa expresa y reiterada del acusado a someterse a su práctica- Fundamento Jurídico Primero.

109 Autorización comentada idóneamente en Sentencias del Tribunal Constitucional como la núm. 25/2005 de 14 de febrero (RTC 2005\25). Según resume esta Sentencia en su Fundamento Jurídico Trece, la justificación constitucional objetiva y razonable ha de basarse en:

«a) El interés público propio de la investigación de un delito, y, más en concreto, la determinación de hechos relevantes para el proceso penal son, desde luego, causa legítima que puede justificar la realización de una intervención corporal o, la obtención de una información en principio reservada a la acción y conocimiento de los demás.

b) Existe también la habilitación legislativa necesaria para la práctica de estas medidas y, por tanto, para la evaluación y toma en consideración de sus resultados, a lo que debe recordarse que la obligación de todos los conductores de vehículos de motor de someterse a las pruebas que se establezcan para la detección de las posibles intoxicaciones por alcohol, está expresamente prevista en una norma con rango de Ley, los arts. 12 y 65 de la Ley sobre Tráfico, Circulación de Vehículos a Motor y Seguridad Vial.

c) Por su parte, en cuanto a la decisión judicial de interesar del centro hospitalario la remisión de dictamen pericial sobre la tasa de alcohol en sangre al resultar esta prueba: 1) que era idónea para alcanzar el fin constitucionalmente legítimo perseguido con ella; 2) que sea necesaria a tal fin, esto es, que no existían otras medidas menos gravosas que, sin imponer sacrificio alguno de los derechos fundamentales a la integridad fisica y a la intimidad, o con un menor grado de sacrificio, fueran igualmente aptas para conseguir dicho fin, y 3) que el sacrificio que imponía de tales derechos no resultaba desmedido en comparación con la gravedad de los hechos y de los indicios existentes.

d) En lo que a la motivación se refiere, la regla de la proporcionalidad de los sacrificios es de observancia obligada al proceder a la limitación de un derecho fundamental y en su virtud, el órgano jurisdiccional debe plasmar el juicio de ponderación entre el derecho fundamental afectado y el interés constitucionalmente protegido y perseguido, del cual se evidencie la necesidad de la adopción de la medida.»

110 Sentencias como la STC núm. 636/2002 de 15 de abril (RTC 2002/636), anulan el valor probatorio del test de alcoholemia por estimar el motivo de vulneración constitucional ya que no se realizó la segunda prueba ni se hizo el ofrecimiento de contrastarla con una análisis sanguíneo. 
cuando se hallen implicados en algún accidente de circulación.» ${ }^{111}$, con lo que sin lugar a dudas podemos apreciar el carácter imperativo de ambas pruebas ${ }^{112}$, de forma que ambas son obligatorias y están orientadas a garantizar el acierto en el resultado, por lo que en definitiva, considero que se puede concluir que la negativa a someterse a cualquiera de ellas constituye una conducta subsumible en el tipo estudiado, ya que podríamos considerar la segunda de las pruebas necesaria para asegurar la eficacia probatoria de la primera medición que de esta forma, no se encontraría contrastada.

El problema surge cuando esa segunda prueba se ha interpretado por algunos tribunales como un beneficio del conductor, y por lo tanto, su negativa se ha considerado como una renuncia a su derecho, de manera que hay resoluciones que concluyen que de efectuarse la primera prueba, la segunda sólo tiene el carácter de constituir una garantía, de modo que puede ser renunciada por el interesado sometido al test ${ }^{113}$. También un sector doctrinal afirma que la segunda negativa puede considerarse más leve en su ofensividad ${ }^{114}$.

111 Y que artículo 21 del Reglamento General de Circulación recoja: «Todos los conductores de vehículos y de bicicletas quedan obligados a someterse a las pruebas que se establezcan para la detección de las posibles intoxicaciones por alcohol. Igualmente quedan obligados los demás usuarios de la vía cuando se hallen implicados en algún accidente de circulación (artículo 12.2, párrafo primero, del texto articulado).

Los agentes de la autoridad encargados de la vigilancia del tráfico podrán someter a dichas pruebas:

a) A cualquier usuario de la vía o conductor de vehículo implicado directamente como posible responsable en un accidente de circulación.

b) A quienes conduzcan cualquier vehículo con síntomas evidentes, manifestaciones que denoten o hechos que permitan razonablemente presumir que lo hacen bajo la influencia de bebidas alcohólicas.

c) A los conductores que sean denunciados por la comisión de alguna de las infracciones a las normas contenidas en este reglamento.

d) A los que, con ocasión de conducir un vehículo, sean requeridos al efecto por la autoridad o sus agentes dentro de los programas de controles preventivos de alcoholemia ordenados por dicha autoridad.»

112 Aunque también con respecto a este extremo hay diferencias de criterio, autores como VARONA GÓMEZ, D., La Negativa a la Práctica de las Pruebas de Alcoholemia, Actualidad Penal, núm. 48, 1996-2, p. 971, se manifiestan a favor de la obligatoriedad de esta segunda prueba; otros como DOMÍNGUEZ IZQUIERDO, E.M., La Conducción Bajo la Influencia de Drogas Tóxicas o Bebidas Alcohólicas y la Negativa a Someterse a las Pruebas Dirigidas a la Comprobación de Tales Hechos, en MORILLAS CUEVA, L., Delincuencia en Materia de Tráfico y Seguridad Vial: aspectos penales, civiles y procesales, Ed. Dykinson, Madrid, 2007, p. 288, mantienen un menor desvalor de la segunda prueba con respecto a la primera.

113 Como muestra, véase este fragmento de la SAP de Barcelona núm. 503/2006 de 28 de marzo (JUR 2006/296994).

114 RODRÍGUEZ FERNÁNDEZ, I., La Conducción bajo la Influencia de Bebidas Alcohólicas, Drogas Tóxicas, Estupefacientes y Sustancias Psicotrópicas, cit., p. 140.

(C) UNED. Revista de Derecho UNED, núm. 13, 2013 
Por ello la Fiscalía General encontró necesario recordar la necesidad de esa segunda prueba en la Circular núm. 10/2011 a la que ya hemos hecho mención, y en la Conclusión Séptima de este texto establecía que, «Sólo se ejercitará la acción penal, como regla general, cuando la citada tasa del tipo del artículo 379.2 inciso 2 se constate en las dos pruebas reglamentarias de alcoholemia, computando los márgenes normativos de error conforme a la OM/ITC/3707 y siempre que se haya observado en su práctica lo dispuesto en los arts. 20 a 26 del RGCir. Asimismo, se darán instrucciones a la Policía de Tráfico para que al atestado se una la documentación que permita calcular el error normativo y, en el caso de ser imposible su aportación, se aplicará el margen máximo contemplado en la norma. También se aportará la ficha o reseña de signos y es conveniente que el atestado incluya, en su caso, los datos pertinentes sobre maniobras irregulares».

En cambio, sí que parece ser una cuestión pacífica el carácter garantista y voluntario que corresponde a la analítica de sangre y que como ya hemos mencionado, alude al «derecho que le asiste [al interesado] a contrastar los resultados obtenidos en las pruebas de detección alcohólica por aire espirado mediante análisis adecuados...» ${ }^{115}$, si bien la jurisprudencia es unánime al interpretar que el derecho a este análisis de contraste surge cuando el interesado se ha sometido a las pruebas reglamentarias y por lo tanto, sólo despliega su eficacia cuando ya se han realizado las de aire espirado.

Por último, e independientemente a la sanción que pudiera recaer sobre el sujeto que se niega al sometimiento del test del alcohol, hay que tener en cuenta que ante la carencia de este dato el juzgador deberá evaluar el resto de las pruebas que pudieran acreditar la conducción bajo esta ingesta alcohólica. Y la relevancia del valor de estas pruebas también es recordada por la Fiscalía General en la Conclusión Cuarta de la Circular núm. 10/2011 donde se recoge que, "Se velará por que en los atestados se consignen las circunstancias de la vía, las metereológicas, densidad del tráfico, riesgos concurrentes y las demás a que alude el artículo 19.1 de la LSV (en este sentido Consulta 1/2006 FGE). También ha de hacerse una descripción con fotografías de la señal, ubicación, visibilidad y estado material. Junto a ello deberán indicarse, asimismo, las características de la vía, vehículo y las circunstancias del conductor a efectos de determinar las limitaciones de velocidad aplicables. Los Sres. Fiscales darán instrucciones al respecto a la Policía Judicial de Tráfico (artículo 773.1 LECr) y solicitarán, cuando proceda, que se complete la investigación policial.

115 Fragmento de la SAP de Burgos núm. 185/2010 de 7 de septiembre (JUR 2010/334620), citada por su ejemplaridad. 
Todo ello a los efectos de diferenciar los casos del artículo 379.1 de los del artículo 380 CP.»

De modo que ante esta negativa, las características que presenta el conductor en el momento de la detención serán de singular importancia, y entre ellas el olor a alcohol, la evidencia de rojeces en sus mejillas y nariz, los ojos brillantes, las pupilas dilatadas, el habla pastosa, la falta de conexión lógica en las expresiones, o el movimiento oscilante de 1a verticalidad del cuerpo. Como vemos, todos elementos que más bien, podrían ser reconocidos como pruebas indiciarias ${ }^{116}$ más que como pruebas directas, aunque el Tribunal Constitucional ha reconocido en numerosas ocasiones el valor esencial de estas pruebas.

Así, por citar una muestra, la Sentencia del Tribunal Constitucional núm. 174/1985 de 17 de diciembre (RTC 1985/174) establece que, "es un hecho que en los juicios criminales no siempre es posible esa prueba directa por muchos esfuerzos que se hagan para obtenerla. Prescindir de la prueba indiciaria conduciría, en ocasiones, a la impunidad de ciertos delitos y, especialmente, de los perpetrados con particular astucia, lo que provocaría una grave indefensión social.»

No obstante a lo anterior, en el juicio oral se han de valorar las pruebas practicadas según criterios de oralidad e intermediación, observando el Tribunal Constitucional que «la influencia de bebidas alcohólicas constituye un elemento normativo del tipo penal que, consecuentemente, requiere una valoración del juez para determinar si el acusado se encontraba afectado por el alcohol» ${ }^{117}$, para lo cual se

116 Es doctrina consolidada por el Tribunal constitucional que, «a falta de prueba directa, la prueba de cargo puede ser indiciaria, siempre que se cumplan los siguientes requisitos, que permiten distinguirla de las simples sospechas: a) que parta de hechos plenamente probados y b) que los hechos constitutivos de delito se deduzcan de esos indicios a través de un proceso mental razonado y acorde con las reglas del criterio humano, explicitado en la sentencia condenatoria. Nuestro control de la razonabilidad del discurso, esto es, de la solidez de la inferencia puede llevarse a cabo tanto desde el canon de su lógica o coherencia (siendo irrazonable cuando los indicios constatados excluyan el hecho que de ellos se hace derivar o no conduzcan naturalmente a él), como desde el de su suficiencia o carácter concluyente, excluyéndose la razonabilidad por el carácter excesivamente abierto, débil o indeterminado de la inferencia (SSTC núm. 189/1998, de 28 de septiembre [RTC 1998/ 189], Fundamento de Derecho Tercero; núm. 220/1998, de 16 de noviembre [RTC 1998, 220], Fundamento de Derecho Cuarto; y, más recientemente, núm. 135/2003, de 30 de junio [RTC 2003, 135], Fundamento de Derecho Segundo; núm. 170/2005, de 20 de junio [RTC 2005, 170], Fundamento de Derecho Cuarto; núm. 74/2006, de 13 de marzo [RTC 2006, 74], Fundamento Jurídico Cuarto; núm. 43/2007, de 26 de febrero [RTC 2007, 43], Fundamento de Derecho Séptimo)».-Fundamento de Derecho Segundo de la STC 174/1985 de 17 de diciembre (RTC 1985/ 174).

117 Argumento éste reiterado en resoluciones como la SSTC núm. 148/85 (RTC 1985/148); núm. 22/88 (RTC 1988/ 22); núm. 24/1992 (RTC 1992/ 24); núm. 252/1994 (RTC 1994/ 252), y núm. 254/1994 (RTC 1994/ 254), entre otras muchas. 
reitera que han de emplearse todos los medios de prueba obrantes, no siendo la prueba de impregnación alcohólica la única para la condena por el delito enjuiciado ni tampoco prueba imprescindible para su existencia ${ }^{118}$.

Y es por la relevancia de la valoración probatoria de cada caso, por lo que son muchas las Sentencias que comentan una posible vulneración del derecho a la presunción de inocencia ${ }^{119}$, entre ellas, el Auto del Tribunal Supremo núm. 675/2013 de 7 de marzo (ATS 33173/2013) que señala que, «las posibles vulneraciones del derecho a la presunción de inocencia, consagrado en el artículo 24.2 de nuestra Constitución, ha de limitarse a la comprobación de tres únicos aspectos, a saber: I) que el Tribunal juzgador dispuso, en realidad, de material probatorio susceptible de ser sometido a valoración; II) que ese material probatorio, además de existente, era lícito en su producción y válido, por tanto, a efectos de acreditación de los hechos; y III) que los razonamientos a través de los cuales alcanza el Juez de instancia su convicción, debidamente expuestos en la sentencia, son bastantes para ello, desde el punto de vista racional y lógico, y justifican, por tanto, la suficiencia de dichos elementos de prueba (SSTS 634/2012 y 668/2012).»

En definitiva, esta presunción expresa «una garantía objetiva $e$ implícita en el sistema de los derechos fundamentales, cuya vigencia y posición preferente en el Estado de Derecho que la Constitución instau-

118 Así, la prueba de la influencia del alcohol puede venir dada por diversas vías que pueden confluir o no, tales como la constatación de una conducción irregular, contraria a las normas del tráfico rodado de la que se pueda evidenciar una dificultad en el control de la misma por parte del conductor; por la presencia en éste de determinados síntomas de descoordinación psicomotora que haga incompatible su estado con una conducción segura; por un grado de impregnación alcohólica tan elevado que imposibilite por sí para una conducción estable. Adquiere así relevancia cualquier medio de prueba, particularmente tanto de carácter testifical como las legales y reglamentariamente practicadas para obtener el grado de impregnación alcohólica. -Fundamento Jurídico Segundo Sentencia del Tribunal Constitucional núm. 174/1985 de 17 de diciembre (RTC 1985/174).

119 Sobre la infracción del principio de presunción de inocencia, este derecho viene consagrado en nuestro sistema con rango de derecho fundamente e implica que toda persona acusada de un delito debe ser considerada inocente hasta que se demuestre su culpabilidad con arreglo a la Ley (artículo 11 Declaración Universal de los Derechos Humanos (LEG 1948, 1); artículo 6.2 Convenio para la Protección de los Derechos Humanos y de las Libertades Fundamentales (RCL 1979, 2421), y artículo 14.2 Pacto Internacional de Derechos civiles y Políticos (RCL 1977, 893) -así manifestado entre otras, en las SSTS como las 25/2008 (RJ 2008, 2693), o 575/2008 (RJ 2008, 5707).

La doctrina también ha cuestionado la vulneración de este Principio, véase por su interés, QUERALT JIMÉNEZ, J.J., Derecho Penal Español. Parte Especial, Ed. Atelier, Barcelona, 2008, p. 926. 
ra exige que los actos que lo vulneren carezcan de eficacia probatoria en el proceso»-Fundamento de Derecho Séptimo de la Sentencia núm. 25/2005 de 14 febrero (RTC 2005 25).

De manera que por un lado es necesaria una correcta defensa social y por el otro, la constitucional obligación de interpretar las pruebas a la luz de este derecho a la presunción de inocencia, lo que a mi juicio provoca que adquiera gran importancia la necesidad de acreditación de pruebas objetivas que no tengan que estar sujetas a una subjetiva interpretación. Y es por esta importancia en el enjuiciamiento del delito que nos ocupa por lo que insisto que no considero desproporcionado el castigo a la negativa a someterse a las pruebas, e incluso que tal negativa tenga incidencia en la interpretación de los síntomas que pudiera reflejar el conductor como un claro indicio de su intención de ocultar una tasa de alcohol inadmisible. Más aún porque ante esta negativa la valoración del resto de las pruebas no dejará de ser subjetiva e insegura ${ }^{120}$, por lo que entiendo proporcionada y ajustada a derecho la elevación de la negativa a realizarse la prueba a la categoría de delito, ya que dejar las misma como una mera sanción administrativa pondría en entredicho la eficacia del inciso segundo del artículo 379.2, al entenderse que aquellos conductores que pese a su elevada tasa alcohólica no hubieran manifestado apenas signos externos en la conducción, pudieran quedar impunes y tan sólo sancionados administrativamente por esta negativa. Para mí es cierto que la protección colectiva que pretende garantizarse mediante el tipo de peligro abstracto del artículo 379.2 se desploma sin la sanción penal a la negativa del artículo $383^{121}$, por lo que la dimensión penal de esta negativa la considero sobradamente justificada por la función que ésta tiene en la detección del delito de conducción etílica del artículo 379.2. Si bien, también he de decir que secundo la crítica de su exceso punitivo, y de que hubiera sido suficiente con equiparar su castigo al dispuesto para la conducción etílica ${ }^{122}$ y que podríamos cuestionar, como hacen numerosos autores, el hecho de que la pena prevista en el artículo 383 sea superior a la del $379.2^{123}$.

120 GUÉREZ TRICARICO, P., Influencia del Alcohol y Conducción Peligrosa en los Delitos contra la Seguridad del Tráfico, La Ley, núm. 6338, 2005, p. 5.

121 Con el mismo criterio MARTÍN LORENZO, M., Negativa a Someterse a las Pruebas de Medición de Alcohol y Detección de Drogas, en Gutiérrez Rodríguez, M. (Coord.), Protección Penal de la Seguridad Vial, Ed. Tirant lo Blanch, Valencia, 2009, p. 328.

122 Idem. p. 329.

123 Criticado por muchos, sin ánimo de ser excluyente, por su interés véase FERNÁNDEZ BAUTISTA, S., El Delito de Negativa a la Realización de las Pruebas de Alcoholemia, en Mir Puig, S. y Corcoy Bidasolo, M. (Dirs.), Seguridad Vial y Derecho Penal, Ed. Tirant lo Blanch, Valencia, 2008, p. 205. 
Pues bien, a tenor de todo lo expuesto podemos formular las siguientes Conclusiones que espero inviten a la reflexión acerca del tema que hemos tratado.

\section{CONCLUSIONES}

La última Memoria de la Fiscalía General del Estado a la que tenemos acceso a la fecha de presentación de este trabajo -la de 2012nos advierte que del total de 702 conductores fallecidos que fueron analizados, el 45,01 por 100 de los casos -316- arrojó un resultado positivo a la presencia de alcohol y/o drogas y/o psicofármacos ${ }^{124}$. Este dato nos lleva a la reflexión acerca de que aún no existe una conciencia social consolidada acerca de la peligrosidad de conducir bajo el efecto de determinadas sustancias como es el alcohol.

Recordemos que la reforma operada por la L.O 5/2010 modifica la pena a imponer sustituyendo la previsión anterior consistente en castigar estas conductas con una pena de prisión o una pena de multa y trabajos en beneficio de la comunidad, por una triple alternativa consistente en castigar las conductas con pena de prisión, pena de multa o pena de trabajos. Y por esta modificación de la condena a imponer la citada Memoria de la Fiscalía General también advierte en 2012 un descenso considerable en el número de internos en Centros Penitenciarios cuya pena principal lo es por un delito contra la seguridad vial. Este descenso lo relaciona con que el recurso a la pena de prisión se reserva para los supuestos más graves o de multirreincidencia ${ }^{125}$.

Por otra parte, también argumenta la Fiscalía General que el artículo 385 ter permite rebajar en un grado las penas de prisión previstas para los delitos de los artículos 379, 383, 384 y 385, «en atención a la menor entidad del riesgo causado y demás circunstancias del hecho», y que esta norma va inequívocamente dirigida a restringir el ingreso efectivo en prisión, en particular en los delitos de los artículos 379 y 384 . En ellos la pena tipo es de 3 a 6 meses de prisión -con la multirreincidencia del artículo $66.1 .5^{\circ}$ puede llegar a 9-, por lo que en atención a los artículos 80 a 89 relativos a las condiciones para suspender o sustituir las penas privativas de libertad, va a ser muy probable que en caso de optar el juzgador por la condena de cárcel ésta no se haga efectiva.

\footnotetext{
124 Pág.918 y ss. de esta Memoria.

125 Idem., p. 933.
} 
Tengamos en cuenta que ante los delitos que analizamos hay quien apunta la poco aconsejable expansión del Derecho Penal ${ }^{126}$ y un uso indebido de este Derecho ${ }^{127}$, y ello pese a que no podemos negar el mayor efecto intimidador de este derecho por las consecuencias punitivas que el mismo supone.

A mi juicio, ante el tipo de conductas descritas donde el conductor pone en un riesgo fatal la seguridad del tráfico y con ésto, las vidas del resto de personas involucradas en esta seguridad no estoy de acuerdo con que el sistema penal no sea eficaz y efectivo para controlar el peligro generado por la circulación de los vehículos de motor, y que un mayor endurecimiento de las sanciones y de las figuras típicas puede llevar a un efecto contrario al deseado ${ }^{128}$, ya que para estos casos sí que justifico la utilización disuasoria de la intervención penal, e incluso dentro de la misma, de la condena de cárcel.

$\mathrm{Y}$ es que incluso ante la posibilidad de que esta condena quede en suspenso o sustituida por otra de menor calado, o que al autor le sea aplicada una condena de multa o de trabajos, existe a mi juicio un riesgo a que socialmente se pueda interpretar que estas infracciones tan graves son tratadas de manera laxa por los tribunales, ante el riesgo de que aflore una conciencia social que equipare la suspensión de la pena de cárcel o la imposición de una multa o de un trabajo social a una aparente impunidad de una conducta tan reprochable.

Es por lo que resumidamente, y según los datos estadísticos referenciados por la Fiscalía General, no tengo confianza en la eficacia preventiva de la multa o de los trabajos para el infractor de este tipo de delitos, y no comparto la opinión de que para la erradicación de estas conductas han de instrumentarse adecuadas políticas de acción social, campañas de sensibilización en los medios de comunicación y en las escuelas, y a través de un reforzamiento de la actuación inspectora y sancionadora de la administración ${ }^{129}$, ya que a mi juicio todas estas medidas hacen su función sí, pero dudo que tengan un eficaz efecto disuasorio para el autor. Estas campañas de divulgación

126 MORILLAS FERNÁNDEZ, D.L., La Influencia Directa del Alcohol..., cit., p. 215.

127 QUERALT, J.J., El Nuevo Derecho Penal Vial, en Mir Puig, S. y Corcoy Bidasolo, M. (Dirs.), Seguridad Vial y Derecho Penal, Ed. Tirant lo Blanch, Valencia, 2008, p. 65.

128 MARTÍNEZ ARRIETA, A., Derecho Penal y Seguridad Vial, en AA.VV, Derecho Penal y Seguridad Vial, Ed. Aranzadi, Navarra, 2007, p. 24.

${ }_{129}$ MARTÍNEZ ARRIETA, A., Derecho Penal y Seguridad Vial, en AA.VV, Derecho Penal y Seguridad Vial, Ed. Aranzadi, Navarra, 2007, p. 27. 
o las medidas educativas a desarrollar sin duda tienen su valor hacia una mayor concienciación y sensibilidad social del problema, pero para mí son un reforzamiento y no podemos depositar en ellas el tratamiento de hechos tan graves como los que analizamos.

Es cierto que el interés legítimo del legislador es eminentemente funcional ${ }^{130}$ y por ese sentido teleológico de la norma penal que protege aquí la seguridad vial, justifico una intensa intervención penal en el delito de análisis, acompañado como no de cualquier medida sensibilizadora como las descritas cuyo efecto siempre es positivo. Y es que resulta reiterada la valoración que secundo acerca de que la conducción de vehículos a motor es sin duda una de las actividades que crean un mayor riesgo para la vida y la integridad de las personas que son valores máximos a tutelar ${ }^{131}$, y es por este motivo por el que estoy en contra de que el reproche penal de estas conductas desvirtúe en algún momento la naturaleza de última ratio de la norma penal $^{132}$, ya que considero que la relevancia del bien tutelado justifica sobradamente este reproche.

Por lo que a mi juicio incluso la condena de multa o de trabajos en beneficio de la comunidad habría de estimarse con cierta prudencia, ya que ante aquellos supuestos en los que el sujeto actuó con un evidente menosprecio a la vida del resto de las personas relacionadas con su conducción -por desarrollar ésta con una tasa de alcohol mayor a la objetivada y pese a que por todos es conocida la merma que esta ingesta conlleva en las habilidades que han de ser requeridas a cualquier conductor- encuentro justificada la condena de cárcel por alcanzar aquí y ante este tipo de incumplimientos todo su sentido el castigo que la misma comporta a tenor de la función retributiva y disuasoria de esta pena, y porque entiendo que en determinados casos como los aludidos la multa o los trabajos pueden resultar una vaga condena en atención al grave desvalor de la conducta del autor.

Al respecto resulta relevante que ya en 2006 el Director General de Tráfico ${ }^{133}$ afirmara que "toca reformar el Código Penal para dar

130 MARTÍN LORENZO, M., Negativa a Someterse a las Pruebas de Medición de Alcohol y Detección de Drogas, cit., p. 321.

131 CARBONELL MATEU, J.C., La Reforma del Tratamiento Penal de la Seguridad Vial, en Morillas Cueva, L. (Coord.), Delincuencia en Materia de Tráfico y Seguridad Vial, Ed. Dykinson, Madrid, 2007, p. 390.

132 MORILlAS CUEVA, L., Delitos contra la Seguridad del Tráfico: una preocupada reflexión global, en Morillas Cueva, L. (Coord.), Delincuencia en Materia de Tráfico y Seguridad Vial, Ed. Dykinson, Madrid, 2007, p. 435.

133 Véase comparecencia del Director General de Tráfico en el Congreso de Diputados de 22 de febrero de 2006, en Diario de Sesiones, Comisiones, núm. 489, 2006. 
coherencia al sistema, para adecuarlo a la demanda social, para actualizarlo de acuerdo con la política de seguridad vial».

En definitiva, es nuestra propia vida la involucrada en esta seguridad vial y este bien merece de una eficaz protección penal con todo el efecto disuasorio que su intervención puede suponer, y siempre claro está, con el respeto a todas las garantías sustantivas y procesales que hemos analizado en Apartados anteriores.

\section{REFERENCIAS BIBLIOGRÁFICAS}

ALONSO RIMO, A., La Negativa a Someterse a las Pruebas de Detección de Alcohol, Drogas Tóxicas o Sustancias Similares como Modalidad de Desobedencia Penal, en Revista Derecho y Proceso Penal, núm. 2, 2003.

BARQUíN SANZ, J. y LUNA DEL CASTILLO, J.D, Seguridad en la Conducción tras Consumo Moderado de Bebidas Alcohólicas, en Morillas Cueva, L. (Coord.), Delincuencia en Materia de Tráfico y Seguridad Vial, Ed. Dykinson, Madrid, 2007.

CALDERÓn CEREZO, A. y Choclán Montalvo, J.A., Código Penal Comentado, Ed. Deusto, Barcelona, 2004.

CARBONELL MATEU, J.C., La Reforma del Tratamiento Penal de la Seguridad Vial, en Morillas Cueva, L. (Coord.), Delincuencia en Materia de Tráfico y Seguridad Vial, Ed. Dykinson, Madrid, 2007.

CARMONA SALGADO, M.J., La Responsabilidad Penal en la Conducción Temeraria, en III Jornadas Nacionales de Derecho y Tráfico, Granada, 1988.

CARMONA SALGADO, C., Delitos contra la Seguridad del Tráfico en Cobo del Rosal, M. (Dir.), Derecho Penal Español. Parte Especial, Ed. Dykinson, Madrid, 2005.

CARMOna SAlGado, M.J., Delitos contra la Seguridad del Tráfico, en Cobo del Rosal, M. (Dir.), Compendio de Derecho Penal Español, Ed.Marcial Pons, Madrid, 2000.

CARPIO BRIZ, D.I., Creación de Grave Riesgo para la Seguridad en el Tráfico, en Mir Puig, S. y Corcoy Bidasolo, M. (Dirs.), Seguridad Vial y Derecho Penal, Ed. Tirant lo Blanch, Valencia, 2008.

CLIMENT DURÁN, C., La Prueba en los Delitos contra la Seguridad del Tráfico, en De Vicente Martínez, R. (Dir), Derecho Penal y 
Seguridad Vial, Ed. Consejo General del Poder Judicial, Madrid, 2007.

DE VICENTE MARTÍNEZ, R., Derecho Penal de la Circulación, Ed. Bosch, Barcelona, 2006.

DÍAZ REVORIO, J., La Prueba de Alcoholemia y sus Consecuencias en los ámbitos Administrativo-Sancionador y Penal, en Anuario Parlamento y Constitución, n. ${ }^{\circ}$ 4, 2000.

DOMÍNGUEZ IZQUIERDO, E.M., La Conducción Bajo la Influencia de Drogas Tóxicas o Bebidas Alcohólicas y la Negativa a Someterse a las Pruebas Dirigidas a la Comprobación de Tales Hechos, en MORILLAS CUEVA, L., Delincuencia en Materia de Tráfico y Seguridad Vial: aspectos penales, civiles y procesales, Ed. Dykinson, Madrid, 2007.

FERNÁNDEZ BAUTISTA, S., El Delito de Negativa a la Realización de las Pruebas de Alcoholemia, en Mir Puig, S. y Corcoy Bidasolo, M. (Dirs.), Seguridad Vial y Derecho Penal, Ed. Tirant lo Blanch, Valencia, 2008.

GALLEGO SOLER, J.I., El Nuevo Delito de Conducción Bajo los Efectos del Alcohol y las Drogas, en Mir Puig, S. y Corcoy Bidasolo, M. (Dirs.), Seguridad Vial y Derecho Penal, Ed. Tirant lo Blanch, Valencia, 2008.

GIL HERNÁNDEZ, Intervenciones Corporales y Derechos Fundamentales, Ed. Marcial Pons, Madrid, 1995.

GÓMEZ PAVÓN, P., El Delito de Conducción Bajo la Influencia de Bebidas Alcohólicas, Drogas Tóxicas y Estupefacientes, Ed. Bosch, Barcelona, 1998.

GONZÁLEZ CUÉLLAR-SERRANO, N., Proporcionalidad y Derechos Fundamentales en el Proceso Penal, Ed. Colex, Madrid, 1990.

GONZÁLEZ RUS, J.J., El Delito de Conducción Bajo la Influencia de Bebidas Alcohólicas y la Prueba de Alcoholemia en la Jurisprudencia Constitucional, en Revista de la Facultad de Derecho de la Universidad de Granada, núm. 15, 1998.

GUÉREZ TRICARICO, P., Influencia del Alcohol y Conducción Peligrosa en los Delitos contra la Seguridad del Tráfico, La Ley, núm. 6338, 2005.

GUTIÉRREZ RODRÍGUEZ, M., Excesos de Velocidad e Intoxicaciones Punibles, en Gutiérrez Rodríguez, M. (Coord.),Protección Penal de la Seguridad Vial, Ed. Tirant lo Blanch, Valencia, 2009. 
IGLESIAS CANLÉ, I.C., La Nueva Regulación de las Medidas de Intervención Corporal en el Artículo 363.2 de la L.E.Crim., en González Cuellar-Serrano, N. (Dir.), Investigación y Prueba en el Proceso Penal, Ed. Colex, Madrid, 2006.

IGLESIAS RÍO, M.A., El Delito de Negativa a Someterse a la Prueba de Alcoholemia, Boletín del Ministerio de Justicia, n. ${ }^{\circ}$ 1845, 1999.

LASCURAÍN SÁNCHEZ, J.A., en Rodríguez Mourullo, G., (Ed.), Comentarios al Código Penal, Ed. Civitas, Madrid, 1997.

LUZÓN PEÑA, D.M., Posibles Reformas de los Delitos de Circulación, en AA.VV., Derecho Penal y Seguridad Vial, Ed. Aranzadi, Navarra, 2007.

MAGALDI PATERNOSTRO, M.J., El Tipo del Artículo 380 del Código Penal: Una Propuesta Interpretativa, en De Vicente Martínez, R. (Dir), Derecho Penal y Seguridad Vial, Ed. Consejo General del Poder Judicial, Madrid, 2007.

MAQUEDA ABREU, M.L., La Idea de Peligro en el Derecho Penal Moderno, en Actualidad Penal, junio, 1994.

MARTÍNEZ ARRIETA, A., Derecho Penal y Seguridad Vial, en AA.VV, Derecho Penal y Seguridad Vial, Ed. Aranzadi, Navarra, 2007.

MARTÍNEZ RUIZ, J., El Delito de Desobedencia a los Agentes de la Autoridad en el ámbito de la Seguridad Vial, en MARTÍN LORENZO, M., Negativa a Someterse a las Pruebas de Medición de Alcohol y Detección de Drogas, en Gutiérrez Rodríguez, M. (Coord.), Protección Penal de la Seguridad Vial, Ed. Tirant lo Blanch, Valencia, 2009.

MOLINA FERNÁNDEZ, R., en Bajo Fernández, M., (Dir.), Compendio de Derecho Penal. Parte Especial, Ed. Ceura, Madrid, 1998.

MORILlAS CUEVA, L., Delitos contra la Seguridad del Tráfico: una preocupada reflexión global, en Morillas Cueva, L. (Coord.), Delincuencia en Materia de Tráfico y Seguridad Vial, Ed. Dykinson, Madrid, 2007.

MORILlAS CUEVA, L., Conducción bajo Bebidas Alcohólicas, Drogas Tóxicas, Estupefacientes o Sustancias y Conducción Temeraria, en Cobo del Rosal, M. y Bajo Fernández, M. (Dirs.), Comentarios a la Legislación Penal, Ed. Editorial de Derecho Reunidas, Madrid, XIV, VOL.2, 1992.

MORILLAS FERNÁNDEZ, D.L., La Influencia Directa del Alcohol como Elemento Integrante del Artículo 379 del Código Penal, en 
Morillas Cueva, L. (Coord.), Delincuencia en Materia de Tráfico y Seguridad Vial, Ed. Dykinson, Madrid, 2007.

MIR PUIG, S., Derecho Penal. Parte Especial, Ed. Tirant lo Blanch, Valencia, 1988.

MIR PUIG, S., Bien Jurídico y Bien Jurídico Penal, en Estudios Penales y Criminológicos, XIV, Ed. Universidad de Santiago de Compostela, Santiago de Compostela, 1991.

MONTANER FERNÁNDEZ, R., Delitos contra la Seguridad Vial, en SILVA SÁNCHEZ, J.M., (Dir.), Lecciones de Derecho Penal. Parte Especial, Ed Atelier, Barcelona, 2011.

MORILlAS CUEVA, L., Derecho Penal Parte General. Fundamentos Conceptuales y Metodológicos del Derecho Penal, Ed. Dykinson, Madrid, 2004.

MORILlAS CUEVA, L., Seguridad contra la Seguridad del Tráfico: Una Preocupada Reflexión Global, en Morillas Cueva, L. (Coord.), Delincuencia en Materia de Tráfico y Seguridad Vial, Ed. Dykinson, Madrid, 2007.

MORILLAS FERNÁNDEZ, D.L., La Influencia Directa del Alcohol como Elemento Integrante del Artículo 379 del Código Penal, en Morillas Cueva, L. (Coord.), Delincuencia en Materia de Tráfico y Seguridad Vial, Ed. Dykinson, Madrid, 2007.

MuÑoz CONDE, F., Derecho Penal. Parte Especial, Ed. Tirant 1 Blanch, Valencia, 2012.

MUÑOZ MEDINA, M.M., La Potestad Sancionadora de la Administración en Matera de Tráfico, BOE, Madrid, 1993.

MUÑOZ MEDINA, M.M., La Potestad Sancionadora de la Administración en Matera de Tráfico, Ed. Colex, Madrid, 2012.

OCHOA CASTELEIRO, A., Los Delitos contra la Seguridad del Tráfico del Artículo 379 del Código Penal desde el Punto de Vista Médico-Legal, en Revista Vasca de Derecho Procesal y Arbitraje, núm. 1, 2006.

OCTAVIO DE TOLEDO Y UBIETO, Sobre el Concepto de Derecho Penal, Ed. Universidad de Madrid, Madrid, 1981.

OLMEDO CARDENETE, M., Aspectos Prácticos de los Delitos contra la Seguridad del Tráfico Tipificados en los Arts. 379 y 380 del Código Penal, Ed. Revista Electrónica de Ciencia Penal y Criminología, núm. 4, 2002. 
ORTS BERENGUER, E., Delitos contra la Seguridad del Tráfico, en Vives Antón, T.S (Dir.), Comentarios al Código Penal de 1995, Ed. Tirant lo Blanch, Valencia, 1996.

QUERALT JIMÉNEZ, J.J., Derecho Penal Español. Parte Especial, Ed. Atelier, Barcelona, 2008.

RODRÍGUEZ FERNÁNDEZ, I., La Conducción Bajo la Influencia de Bebidas Alcohólicas, Drogas Tóxicas, Estupefacientes y Sustancias Psicotrópicas, Ed. Comares, Granada, 2006.

SÁNCHEZ MORENO, J., Negativa a Someterse a las Pruebas de Alcoholemia, Ed. Bosch, Barcelona, 2008.

SILVA SÁNCHEZ, J.M., Consideraciones sobre el Delito del Atr. 340 bis a) $10^{\circ}$ del Código Penal, en Revista Jurídica de Cataluña, núm. 1, Barcelona 1993; y en AA.VV.,Derecho de la Circulación, Ed. Ministerio de Justicia, Madrid, 1993.

SOTO NIETO, F., Conducción Bajo los Efectos de Drogas o Bebidas Alcohólicas, en La Ley, núm. 6167, 2005.

TAMARIT SUMILLA, J.M., De los Delitos contra la Seguridad del Tráfico, en Quintero Olivares, G., Comentarios a la Parte Especial del Derecho Penal, Ed. Aranzadi, Navarra, 1996.

TAMARIT SUMILLA, J.M., Comentarios al Artículo 379, en Quintero Olivares, G. (Dir.), Comentarios al Nuevo Código Penal, Navarra, 2005.

TERRADILlOS BASOCO, J.M., Peligro Abstracto y Garantías Penales, en Quintero Olivares, G. y Morales Prats, F., (Coords.), en El Nuevo Derecho Penal Español. Estudios Penales en Memoria del Profesor José Manuel Valle Muñiz, Ed. Aranzadi, Pamplona, 2001.

VARGAS CABRERA, B., El Delito de Conducción Bajo la Influencia de Bebidas Alcohólicas y Drogas Tóxicas del Artículo 379 C.P., en De Vicente Martínez, R. (Dir), Derecho Penal y Seguridad Vial, Ed. Consejo General del Poder Judicial, Madrid, 2007.

VARONA GÓMEZ, D., La Negativa a la Práctica de las Pruebas de Alcoholemia, Actualidad Penal, núm. 48, 1996-2.

VARONA GÓMEZ, D., El Delito de Negativa a las Pruebas de Alcoholemia Sentencias 161/1997 y 234/1997 del Tribunal Constitucional y la Sentencia del Tribunal Supremo de 9 de diciembre de 1999, La Ley, núm. 1, 2000. 
VILLALBA CARRASQUILLA, F.J., El Endurecimiento de las Penas en lo Delitos de Tráfico como Medida de Mejora de la Siniestralidad, en Mir Puig, S. y Corcoy Bidasolo, M. (Dirs.), Seguridad Vial y Derecho Penal, Ed. Tirant lo Blanch, Valencia, 2008.

VILLANUEVA CAÑADAS, E., Estudio Toxicológico y Médico-Legal del Alcohol, en Gisbert Calabuig, J.A., Medicina Legal y Toxicología, Ed. Elsevier Masson, Barcelona, 1997. 